\title{
Scoping Review of Healthcare Literature on Mobile, Wearable, and Textile Sensing Technology for Continuous Monitoring
}

\author{
N. Hernandez ${ }^{1}$ • L. Castro ${ }^{2}$ - J. Medina-Quero ${ }^{3}$ - J. Favela ${ }^{4}$ - L. Michan ${ }^{5}$. \\ W. Ben. Mortenson ${ }^{6}$
}

Received: 6 April 2020 / Revised: 30 July 2020 / Accepted: 2 December 2020 /

Published online: 1 February 2021

(C) The Author(s), under exclusive licence to Springer Nature Switzerland AG part of Springer Nature 2021

\begin{abstract}
Remote monitoring of health can reduce frequent hospitalisations, diminishing the burden on the healthcare system and cost to the community. Patient monitoring helps identify symptoms associated with diseases or disease-driven disorders, which makes it an essential element of medical diagnoses, clinical interventions, and rehabilitation treatments for severe medical conditions. This monitoring can be expensive and timeconsuming and provide an incomplete picture of the state of the patient. In the last decade, there has been a significant increase in the adoption of mobile and wearable devices, along with the introduction of smart textile solutions that offer the possibility of continuous monitoring. These alternatives fuel a technology shift in healthcare, one that involves the continuous tracking and monitoring of individuals. This scoping review examines how mobile, wearable, and textile sensing technology have been permeating healthcare by offering alternate solutions to challenging issues, such as personalised prescriptions or home-based secondary prevention. To do so, we have selected 222 healthcare literature articles published from 2007 to 2019 and reviewed them following the PRISMA process under the schema of a scoping review framework. Overall, our findings show a recent increase in research on mobile sensing technology to address patient monitoring, reflected by 128 articles published in journals and 19 articles in conference proceedings between 2014 and 2019, which represents $57.65 \%$ and $8.55 \%$ respectively of all included articles.
\end{abstract}

Keywords Smartphones · Wearable devices · Textile technology · Continuous sensing • Remote monitoring

N. Hernandez

hernandez_cruz-n@ulster.ac.uk

Extended author information available on the last page of the article 


\section{Introduction}

In the last decades, we have experienced different challenges derived from global epidemics (e.g. H1N1 [1], Ebola [2], measles [3], dengue fever [4]) that had shifted our political, economic, and healthcare systems. Recently, the fatalities derived from the pandemic of the coronavirus disease (COVID-19) ${ }^{1}$ are rising, and with it, a concomitant increase in the demand of healthcare causing care services to become insufficient. The structure of our healthcare system relies on a centralised hospitalisation, in which ill citizens travel to the clinic to receive a medical diagnosis. While this model has been effective in the past, we are now witnessing a shift in political, economic, and healthcare models, in which the efforts to conserve dwindling resources lie towards using remote technology to address medical care service locally in neighbourhoods and individual homes.

Empowering citizens and patients with technology to enable self-care and remote monitoring can help reduce health expenditures by minimising the number of visits to clinics and hospitals. In the scope of ubiquitous computing research, helping patients to self-manage and remote monitoring aim at providing low-cost everyday home usage due to the advances in sensor, communication, and portable technology. For this paper, we consider mobile, wearable, and textile (MWT) sensing technology and the use of these devices to monitor physical and social behaviour, either individually or collectively. A mobile device may consist of gadgets such as smartphones and tablets [5]. Wearables can offer a discreet and convenient approach to gathering data; some examples of items include watches, fitness trackers, badges, glasses, and similar devices [6]. Textiles are defined as smart if they have intrinsic properties that can respond to the environment and to a user's stimuli. In contrast to currently available technology, they tend to be soft and adopted to smart ensemble garments [7]. These approaches help to improve the user experience by requiring low or no cognitive effort to operate in daily life (a.k.a. naturalistic conditions).

MWT sensing technology makes it possible to monitor a patient's health both longterm and continuously $[8,9]$. Traditional methods of monitoring have frequently relied on admission to hospitals and nursing homes, which can be expensive and often inconvenient to patients. ${ }^{2},{ }^{3}$ In this regard, technology and scientific progress aim at supporting early detection of disease, independent living, enhancing rehabilitation treatment, and assessment of wellbeing. There have been a few systematic reviews in this area. One review focused specifically on sensor-based authentication strategies to maintain patient privacy when using mHealth [10]. A 2018 review [11] of empirical health and wellbeing research on smartphone-based passive sensors identified a variety of limitations in terms of data sharing with participants, weak study designs, limited clinical integration, and privacy concerns.

This paper examines how a broader range of MWT technologies have been permeating the medical field by bringing technological solutions to problems in which continuous monitoring and personalised prescription are critical.

\footnotetext{
$\overline{{ }^{1} \mathrm{https}: / / w w w . w h o . i n t / h e a l t h-t o p i c s / c o r o n a v i r u s ~}$

2 https://www.ons.gov.uk/peoplepopulationandcommunity/healthandsocialcare/healthcaresystem/bulletins/ ukhealthaccounts/2015

${ }^{3}$ https://www.nhs.uk/conditions/coronavirus-covid-19/self-isolation-advice/
} 
Moreover, we present a discussion to illustrate the technological tendencies and challenges. The literature analysis is framed based on the following research questions:

- How is mobile sensing technology being adopted into healthcare research?

- What types of health problems are the focus of MWT sensing technology?

- What is the current status of MWT sensing technologies regarding monitoring platforms or technologies, and how might this affect healthcare trends?

\section{Methodology}

The methodology and eligibility criteria were established a priori. The study was conducted as a scoping review, an approach intended to provide an overview of a diverse body of literature pertaining to a broad topic, as well as a descriptive overview of the reviewed material [12]. This scoping review conducts and reports according to the systematic reviews and meta-analysis (PRISMA) statements [13].

\subsection{Eligibility Criteria}

Original studies that discussed the use of MWT technology in healthcare were eligible for inclusion. The publications were restricted to journals and conference proceedings written in the English language.

Studies were excluded for two main reasons: (1) multiple articles reported on the same study and (2) studies did not evaluate the MWT technology.

\subsection{Information Sources and Search Strategy}

The published works were identified by conducting a systematic literature search through PubMed, which is a free electronic database of citations and abstracts comprised of over 28 million citations for biomedical articles from MEDLINE, life science journals, and online books. It is maintained by the National Center for Biotechnology Information (NCBI) at the National Library of Medicine (NLM). PubMed was used as a resource to concentrate relevant publications aiming to explore the different approaches to cope with medical challenges using MWT technologies and scientific advances. We used the MeSH (Medical Subject Headings) descriptors in order to analyse the literature corpus and bibliometric indicators. MeSH is the NLM-controlled vocabulary thesaurus used for indexing articles for PubMed,

The literature search was supplemented by a manual search of the reference lists of the retrieved articles related to physiological monitoring and wearable and mobile technology. The literature search was conducted using the following MeSH terms: ("Monitoring, Physiologic"[MeSH TERMS]) AND ("Wearable Electronic Devices"[MeSH TERMS] OR "Computers, Handheld"[MeSH TERMS]) and covered a period from 2007 (inclusive) to 2019 (inclusive) due to the introduction of sensorequipped smartphones in 2007 (i.e. the first iPhone). The last literature search update was conducted on March 25th, 2020. 


\subsection{Study Selection}

A PRISMA diagram for the study is provided in Fig. 1, which presents the flow diagram of the scoping review. Selection criteria consisted of articles that describe the used technology in the context of health-related MWT sensing technology. This included articles with any of the following specifications:

- Signal processing of data gathered with mobile sensors in a medical context.

- Hardware and software prototyping for monitoring purposes.

- System/app developments that facilitate the self-reporting of medical conditions/ symptoms.

- Mental medical conditions as derived from health problems.

All identified titles $(n=487)$ were labelled as relevant, irrelevant, and unclear and were further discussed with the consensus of two researchers (JM, NH). The abstract of pre-selected works $(n=394)$ was screened for eligibility by three researchers (JM, LC, $\mathrm{NH}$ ), and internal consistency was reliable (Cronbach's alpha $=0.869)$. The relevant articles $(n=288)$ were retrieved, and the entire texts were independently checked by
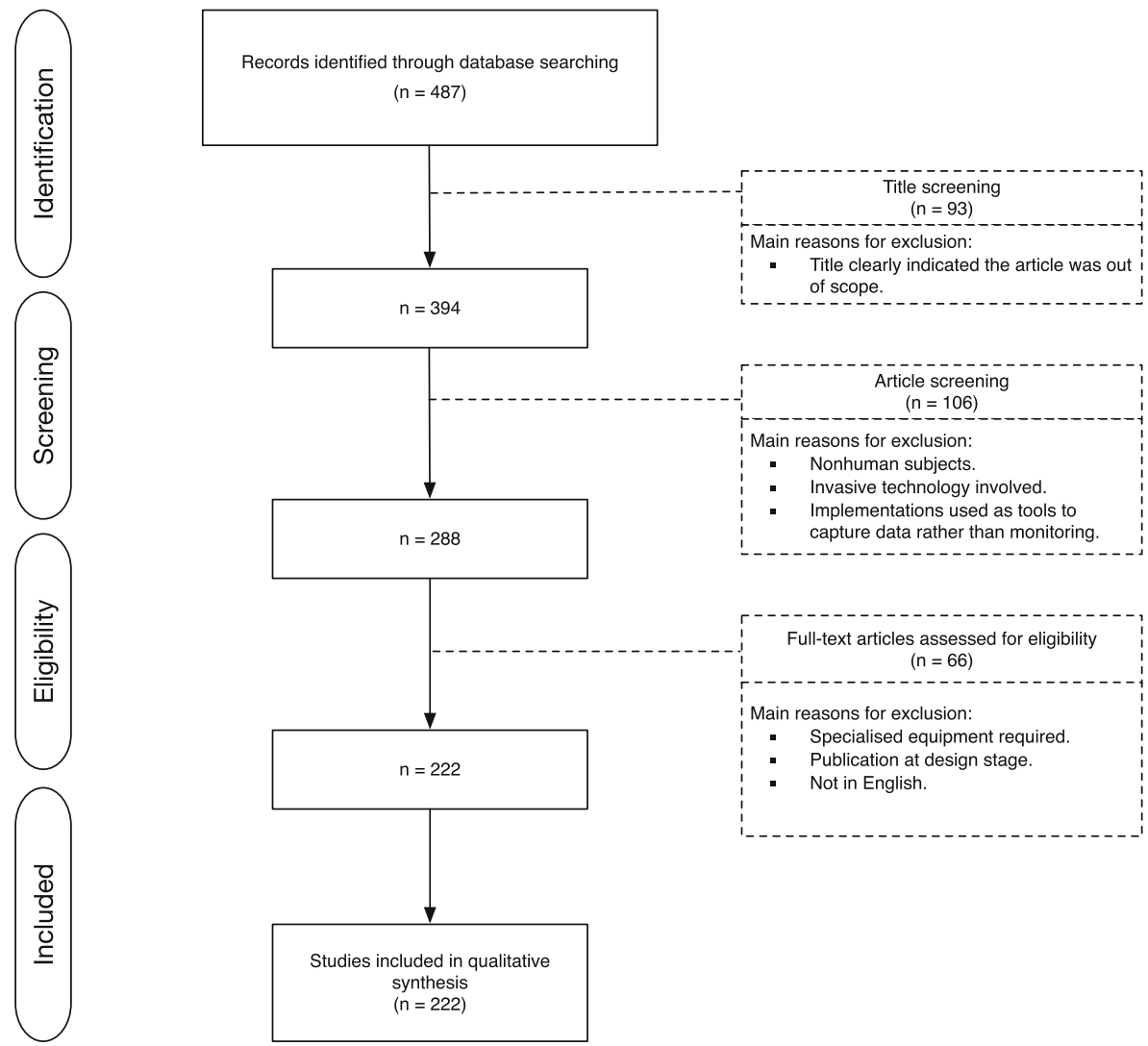

Fig. 1 Flow diagram for the literature search based on the protocol PRISMA. 
three researchers (LC, JM, NH) to assure that the eligibility criteria were satisfied. Through this process, a total of 222 articles were included in the review.

To better understand how engineering approaches have permeated the medical field, we focused on the area of continuous health monitoring. We classified journals in three categories: medical-oriented, representing journals with primarily medical/clinician authors; engineering-focused health journals; and interdisciplinary, representing those journals focused on healthcare from an engineering perspective.

The included studies were reviewed by three of the authors who extracted relevant information from each article including country of origin of the authors/institutions, PubMed article category, type of technology used for sensing (smartphone, wearable, smart textile), type of sensing approach (opportunistic/participatory), type of sensor, location of the sensor, evaluation control, and health condition. Any disagreements were resolved through a discussion among four authors (JF, JM, LC, NH).

\section{Results}

This section presents findings regarding bibliometric analysis (3.1), data analysis towards measuring the maturity of the studies retrieved (3.2), mobile technology (3.3), sensing approach (3.4), sensing technology (3.5), and application in the healthcare field (3.6).

\subsection{Bibliometric Analysis}

In this era of ubiquitous technology and artificial intelligence (AI), the impact of engineering in medicine is increasing. Such collaboration benefits clinicians and enhances the patients' recovery experience, for instance, by personalising medication [14], enabling early diagnosis [15] and treatment of disease [16], and facilitating remote rehabilitation tasks [17], among others. These ground-breaking outcomes are possible through the contributions of multidisciplinary teams between clinicians and engineers.

In this cohort of articles, we can observe that the manuscripts reviewed are published in 85 journals, and according to PubMed, 40.09\% are technology-oriented research. PubMed classifies them into nine main groups: informatics $(n=52)$, technology $(n=$ $23)$, medicine $(n=20)$, health services $(n=18)$, sports medicine $(n=16)$, biotechnology $(n=14)$, health services $(n=14)$, cardiology $(n=13)$, and physiology $(n=12)$.

In Fig. 2, we observe that $45.49 \%$ of the articles $(n=101)$ derived from the medicaloriented journals have explored the adoption of mobile sensing as a healthcare monitoring technique. Some of the approaches target way to evaluate patients' acceptance of wearable/mobile technology, accuracy compared to golden standard equipment, and offer open challenges to the engineering community. Also, Fig. 2 shows that the engineering community $(n=20 ; 9.00 \%)$ altogether with the multidisciplinary effort $(n=101 ; 45.49 \%)$ account for $54.50 \%(n=121)$ of work related to continuous healthcare monitoring. The latter includes technological prototype design, algorithm evaluation, and platform design. In general, 113 (50.90\%) of the articles were published in the last few years (i.e. 2015-2019), depicting the increasing interest in the area.

When analysing the selected articles, one can observe the influence of specific countries by quantifying the number of publications, which is relevant due to the role 


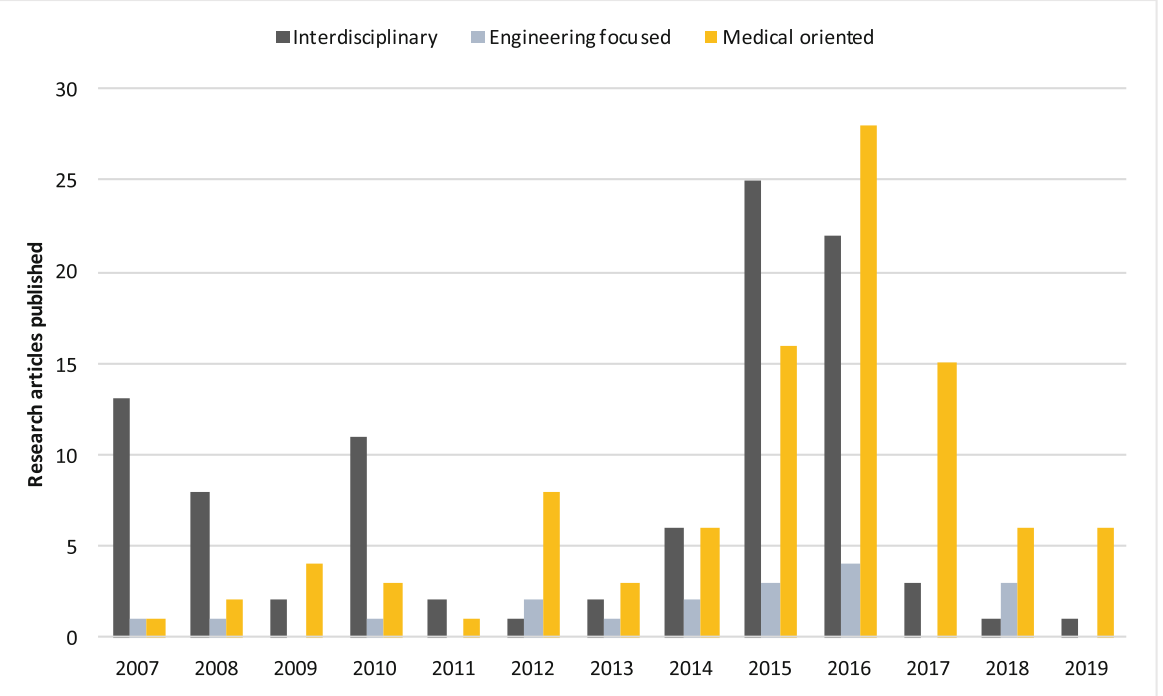

Fig. 2 The number of research articles published in scientific journals. Journals are grouped within three categories: medical-oriented, engineering-focused, and interdisciplinary, involving both the research areas.

taken by the different countries' institutions conducting economic analyses of regulations on medical devices (e.g. Food and Drug Administration in the USA, ${ }^{4}$ Medicines \& Healthcare products Regulatory Agency in the UK, ${ }^{5}$ European Medicines Agency in the EU, ${ }^{6}$ and National Medical Products Administration in China ${ }^{7}$ ). Such analysis includes the cost-benefit assessment of new medication, treatment techniques, diagnosis devices, and the impact on each country's economy, ${ }^{8}$ which are decisions that have a paramount role in the manufacture manage care decision-maker [18], and research $[19,20]$.

In Fig. 3, we show the number of articles classified per country. Each publication has an average of five authors, accounting for 926 authors from 34 countries. In this regard, more than $2 / 3$ of the articles originate from five countries. The USA ranked at the top, with approximately $25 \%$ of authorship as depicted in Fig. 3. Eligible articles included institutions mainly from sixteen countries (USA, UK, Korea, Australia, Germany, Netherlands, Canada, China, Spain, Japan, Italy, Singapore, Finland, France, Ireland, and Norway) that are leading research on users of constant monitoring technologies, which represents the $80.63 \%$ of all articles retrieved in this study.

\subsection{Dissemination Style}

While journal publications involve a robust peer-reviewed process that ensures reliability, conference proceedings consist of scholarly work and discussions, which can have a more flexible review process [21].

\footnotetext{
${ }^{4}$ https://www.fda.gov/about-fda

${ }^{5}$ https://www.gov.uk/government/news/welcome-to-our-new-mhra-website

${ }^{6} \mathrm{https}: / /$ www.ema.europa.eu/en

${ }^{7}$ http://english.nmpa.gov.cn/

${ }^{8} \mathrm{https}$ //www.fda.gov/about-fda/reports/economic-impact-analyses-fda-regulations
} 


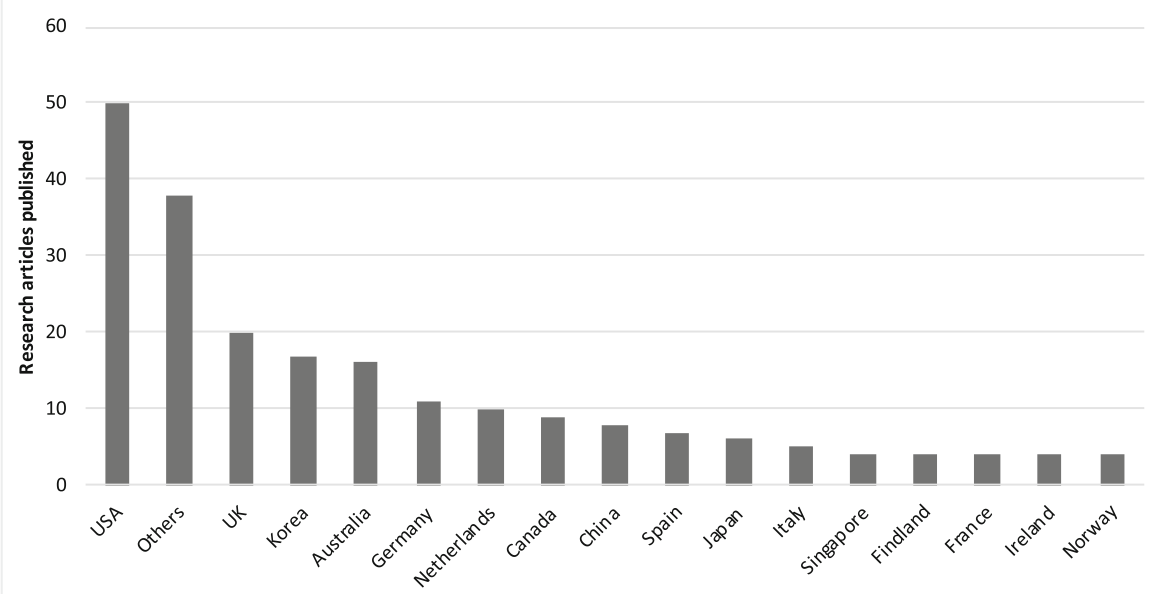

Fig. 3 The number of research articles grouped by the country where the authors' institutions are based.

Considering the publication type as a criterion of reliability illustrates how mobile sensing research is maturing. In Fig. 4, we observe that since 2014 there has been a significant increase in the number of journal articles published when compared to conference proceeding articles, the number of which has remained mostly constant. Of the research articles reviewed, $78.82 \%$ are from journals and less than $21.17 \%$ are from conference proceedings.

Table 1 shows the number of articles published according to their orientation (i.e. medical, engineering, or interdisciplinary). Nearly half of the journal articles published are in medical journals (45.49\%), 57.65\% of which have been available since 2014.

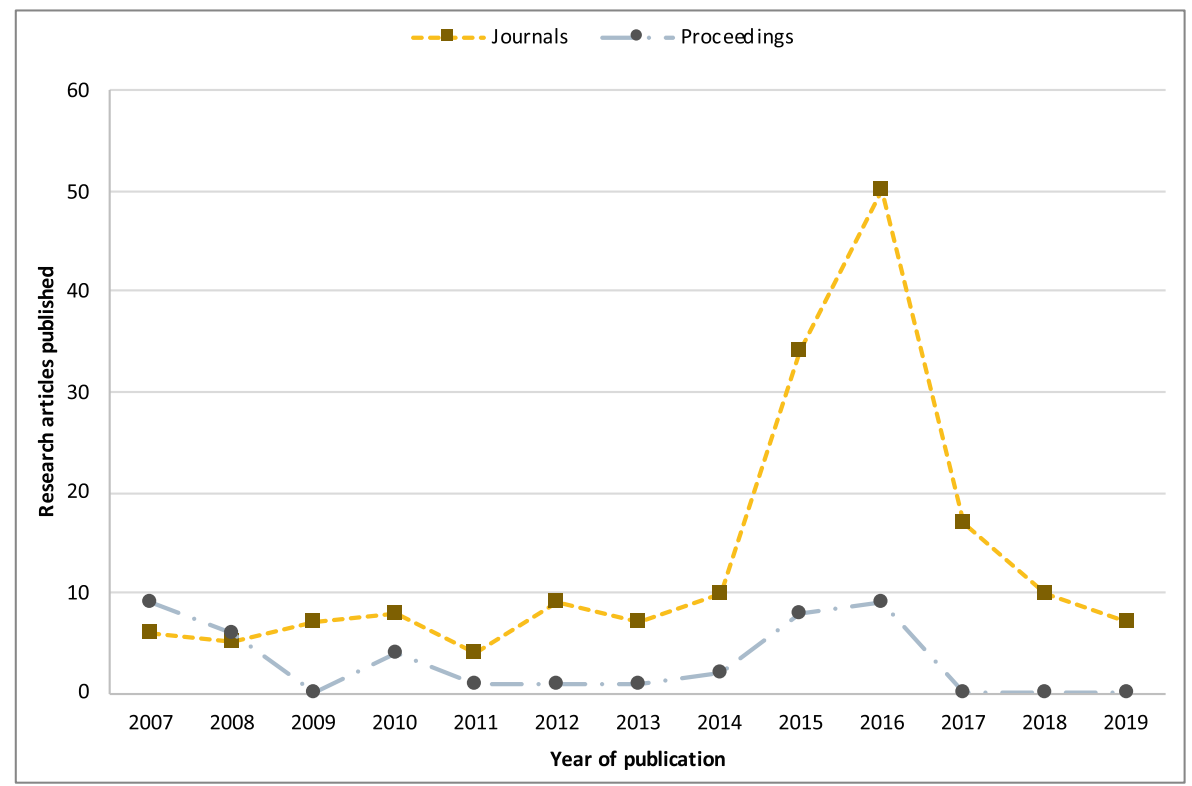

Fig. 4 The number of articles grouped by publication type: journals and conference proceedings. 
Also, $12.76 \%$ of the conference proceedings articles published focused on engineering, while $87.23 \%$ of the proceedings come from interdisciplinary collaborations. This difference provides not only evidence of the interest from the engineering community in addressing some of the medical challenges but the acceptability from the medical community in adopting such approaches. This last statement can be appreciated as all the articles from the medical orientation build upon journal publication type.

Another approach to measuring how mobile sensing has been consolidated might be by identifying quantitative and qualitative research. Qualitative research is exploratory, and it helps to develop hypotheses for quantitative research. Quantitative research can provide broad insights resulting in a recommended course of action [22]. According to the data collected in this scoping review, $13.51 \%$ of projects adopt a randomised controlled trial (RCT), which is a quantitative research method known as the gold standard for the healthcare sector in the medical field (Table 2).

Figure 5 depicts the increase on RCT studies since 2014, which shows an increase in the strength of evidence gathered using this MWT technology, and the ratio in the last 2 years (i.e. 2018, 2019).

\subsection{Research in Mobile, Wearable, and Textile Sensing Technology}

Here we found that the use of smartphones and tablets leads portable technology given its high power and storage capabilities. Smartphones and tablets are followed by wearable gadgets such as fitness trackers and watches that, due to their unobtrusiveness and their continuing connection to the skin, become a convenient choice for the user and a strategic source of data for the researcher. Textiles open new research opportunities, given their distinguishing characteristic of integrating electronics into the manufacturing process. Out of 222 articles, 171 (77.02\%) involved the use of smartphones, 94 (42.34\%) focused on computer-related technology such as wearables, and $11(4.95 \%)$ built on textile and fabric sensing approaches. Figure 6 shows the number of articles published in the last few years, which implies that mobile devices have been a feasible technology for the continuous monitoring of users' health.

\subsection{Sensing Approaches}

In the context of sensing approaches within mobile computing, intrusiveness refers to the undesirable and physical or psychological prominence of a device that interrupts a user's day-to-day activities [53]. Figure 7a illustrates mobile devices as tools to capture data (i.e. a participatory approach) manually and are increasingly being used as non-

Table 1 Publication type grouped within three categories: medical-oriented, engineering-focused, and interdisciplinary involving both types of research areas, as mentioned earlier.

\begin{tabular}{lll}
\hline & Journal & Proceedings \\
\hline Interdisciplinary & 60 & 41 \\
Engineering focused & 14 & 6 \\
Medical oriented & 101 & 0 \\
\hline
\end{tabular}


Table 2 List of articles adopting RCT has a mechanism of validation.

\begin{tabular}{ll}
\hline Year & Publication \\
\hline 2007 & - \\
2008 & {$[23]$} \\
2014 & {$[24,25]$} \\
2015 & {$[26]$} \\
2016 & {$[27-33]$} \\
2017 & {$[34-46]$} \\
2018 & {$[47-50]$} \\
2019 & {$[51,52]$} \\
\hline
\end{tabular}

intrusive and automatic mechanisms for collecting data (i.e. an opportunistic approach). Findings show in Fig. 7 a that $42.56 \%$ of studies collected data opportunistically [54-67] when utilising mobile devices. In contrast, Fig. 7b shows that wearable devices have mostly relied on sensing data opportunistically $(n=86,90.52 \%)$, so that users' day-to-day activities are not interrupted. Except for 2007 and 2012, non-intrusive techniques have dominated the monitoring approach used. Overall, $70.37 \%$ of projects across mobile and wearable technology collected information opportunistically. The lack of participatory projects observed within the gap between 2012 and 2017 suggests that the advances in wearable technology are relevant to research monitoring technique (see Table 3 for details).

Figure 8 groups' devices are based on two general body areas: the upper body where devices are worn/carried, such as glasses, necklaces, and watches, and the lower body where devices are worn/carried on the waist, in a pocket, on the ankle, and in/on the shoes. This scoping review shows that there are three times as many articles about wearable technology than articles about mobile devices that are positioned on the chest/

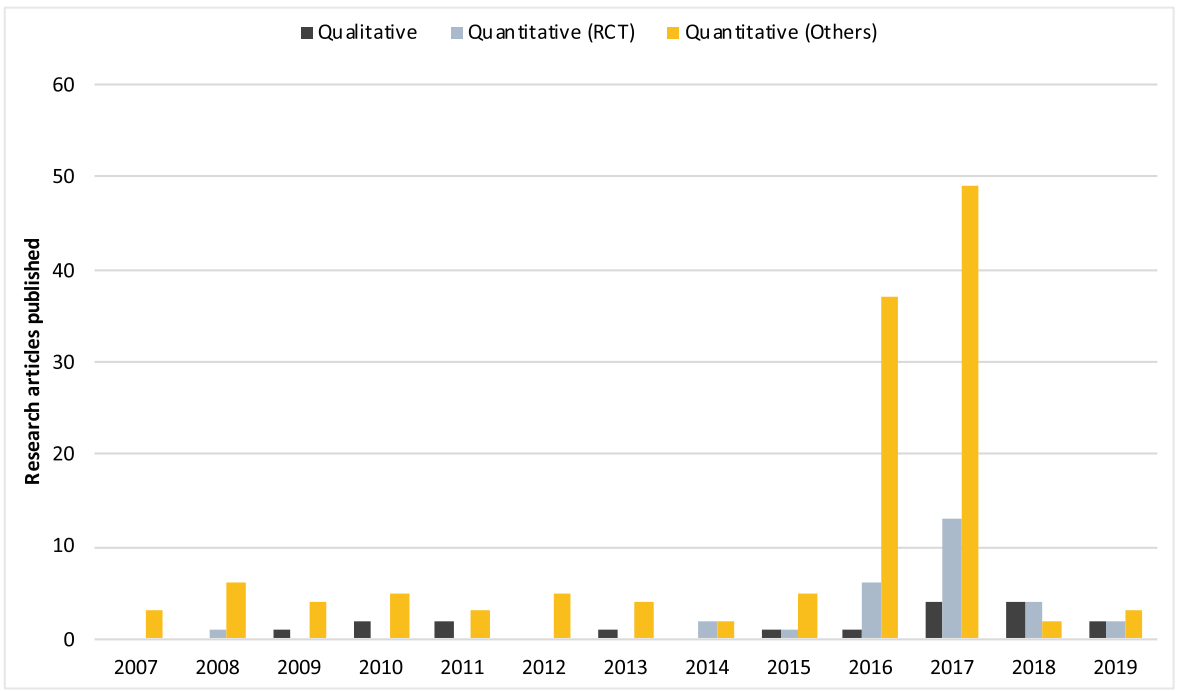

Fig. 5 Validation of research conducted. 


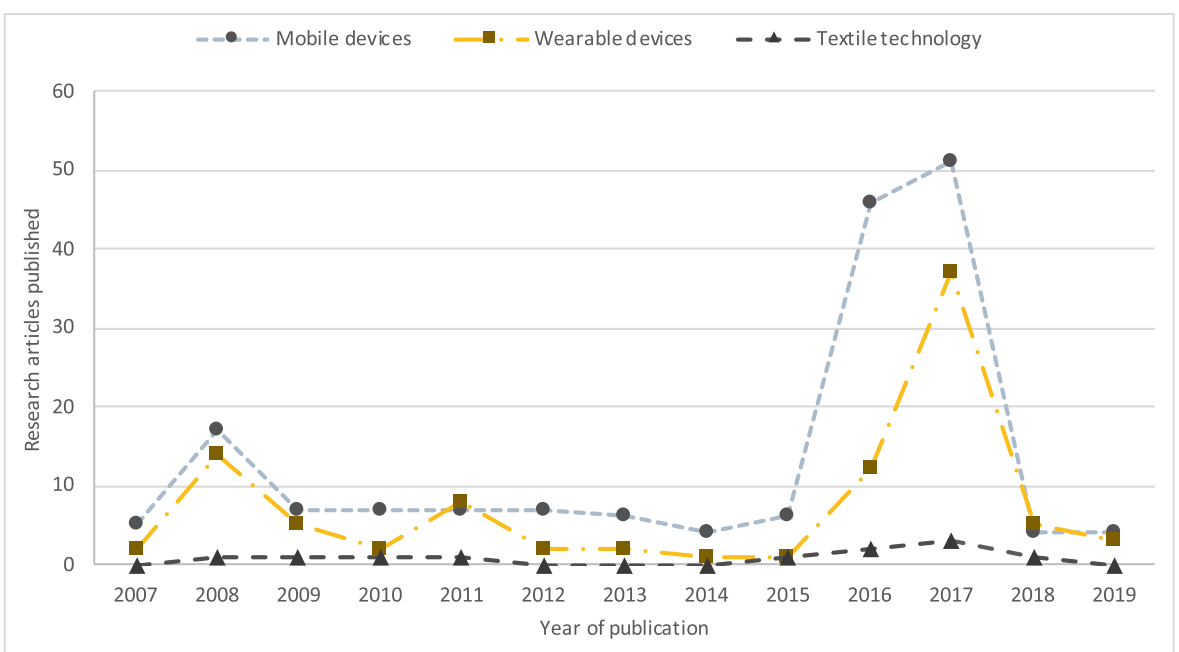

Fig. 6 Comparison of the scientific articles that research continuous health monitoring by using mobile devices or MWT technological approaches.

pectoral zone. Similarly, there are about three times more studies that use wearable devices on the hip/waist $(n=26)$ when compared to mobile devices $(n=7)$.

In general, the least common areas for device placement are the head $(3.33 \%$ [34, $35,104,149,172])$, the upper back $(3.33 \%$ [42, 144, 160, 174, 179]), and the lower back $(1.42 \%[119,162])$ as documented by the reviewed publications (Fig. 8 b).

\subsection{Sensing Technology}

Due to improvements in sensor technology, it is currently possible to non-intrusively capture motor and metabolic health information via users' physical performance and contact with the skin. For example, wrist smartwatches and forearm bands gather information such as skin temperature, pulse waves, $\mathrm{pH}$, blood flow, and electrodermal activity, whereas smartphones can collect data on long-term performance monitoring [5]. Figure 9 presents a taxonomy of the sensor technologies adopted by the studies retrieved in this scoping review. To offer a better overview of sensor adoption, we

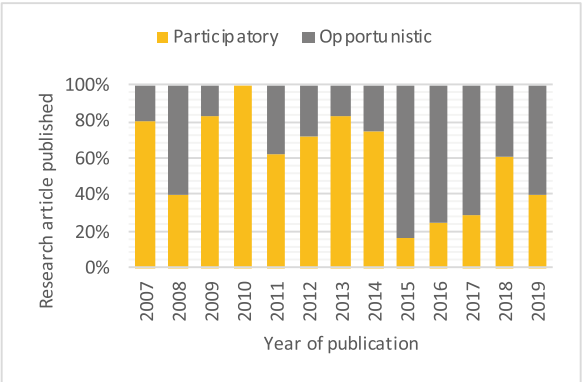

a)

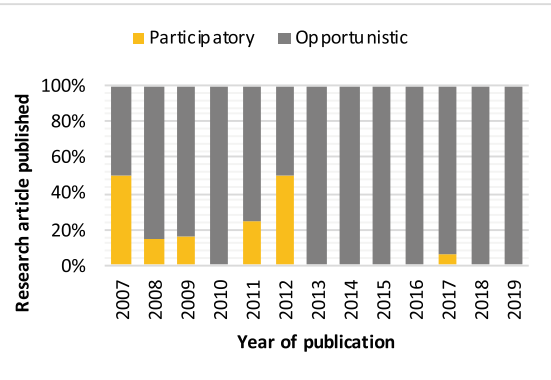

b)

Fig. 7 The sensing approaches used by mobile devices (left) and wearable technology (right). a) Data capture approach of mobile devices, b) Data capture approach of wearable devices. 
Table 3 List of articles presenting details from Fig. 7 to illustrate the sensing approach from mobile devices and wearable technology

\begin{tabular}{|c|c|c|c|c|}
\hline \multirow[t]{2}{*}{ Year } & \multicolumn{2}{|l|}{ Mobile devices } & \multicolumn{2}{|l|}{ Wearable devices } \\
\hline & Opportunistic & Participatory & Opportunistic & Participatory \\
\hline 2007 & [68] & [69-72] & [54] & [72] \\
\hline 2008 & {$[55-63]$} & {$[23,73-77]$} & {$[55,57,58,60-63,73,78-81]$} & {$[76,82]$} \\
\hline 2009 & {$[65]$} & [83-87] & {$[65,84,86-88]$} & [89] \\
\hline 2010 & {$[64]$} & {$[64,90-92]$} & {$[92]$} & None \\
\hline 2011 & {$[66,67,93]$} & [94-98] & {$[95,96,99]$} & [98] \\
\hline 2012 & {$[100,101]$} & [102-106] & [107] & [104] \\
\hline 2013 & {$[108]$} & [109-112] & {$[111,113]$} & None \\
\hline 2014 & [114] & {$[24,25,115]$} & {$[25]$} & None \\
\hline 2015 & {$[116-120]$} & [26] & [117] & None \\
\hline 2016 & $\begin{array}{r}{[27-29,32} \\
121-148]\end{array}$ & $\begin{array}{l}{[27,30,31,124,134} \\
\quad 147,149-155]\end{array}$ & {$[123,148,149,151,156-161]$} & None \\
\hline 2017 & $\begin{array}{r}{[37,43,68} \\
162-187]\end{array}$ & $\begin{array}{l}{[39,42,174,183} \\
\quad 188-197]\end{array}$ & $\begin{array}{l}{[34-38,40,41,167,170,172,174,175,178} \\
\quad 180,188-190,192,198-216]\end{array}$ & $\begin{array}{l}{[39,44,217,} \\
218]\end{array}$ \\
\hline 2018 & None & {$[47,49,50]$} & None & None \\
\hline 2019 & None & {$[52,219]$} & None & None \\
\hline
\end{tabular}

excluded experimental cases by focusing on studies in which at least three articles utilise the technology.

In this context, Fig. 9 shows how electrodes and inertial sensing (e.g. accelerometer, gyroscope) are popular technologies used to extract parameters of interest related to medical conditions such as heart rate monitoring, respiration, sleep tracking, and general motor activities.

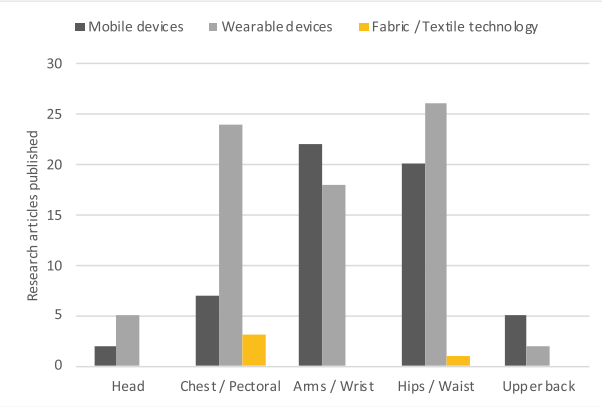

a)

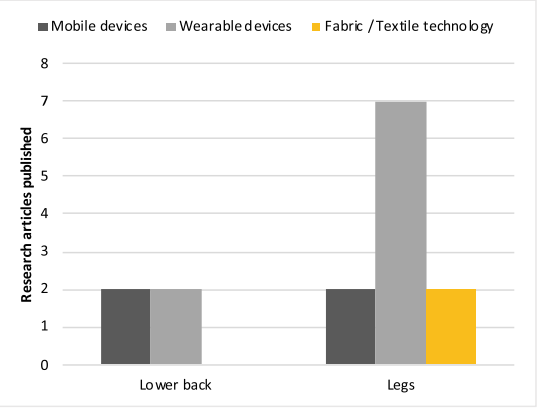

b)

Fig. 8 Comparison of the part of the body where technology is worn/carried. The chart on the left shows the common upper body positions for wearing/carrying devices. The chart on the right shows the common lower body positions for wearing/carrying devices. Note that 88 articles reported having integrated mobile devices as part of a monitoring solution whereby their position was not relevant and not included in the graph. a) Upper body position, b) Lower body position. 


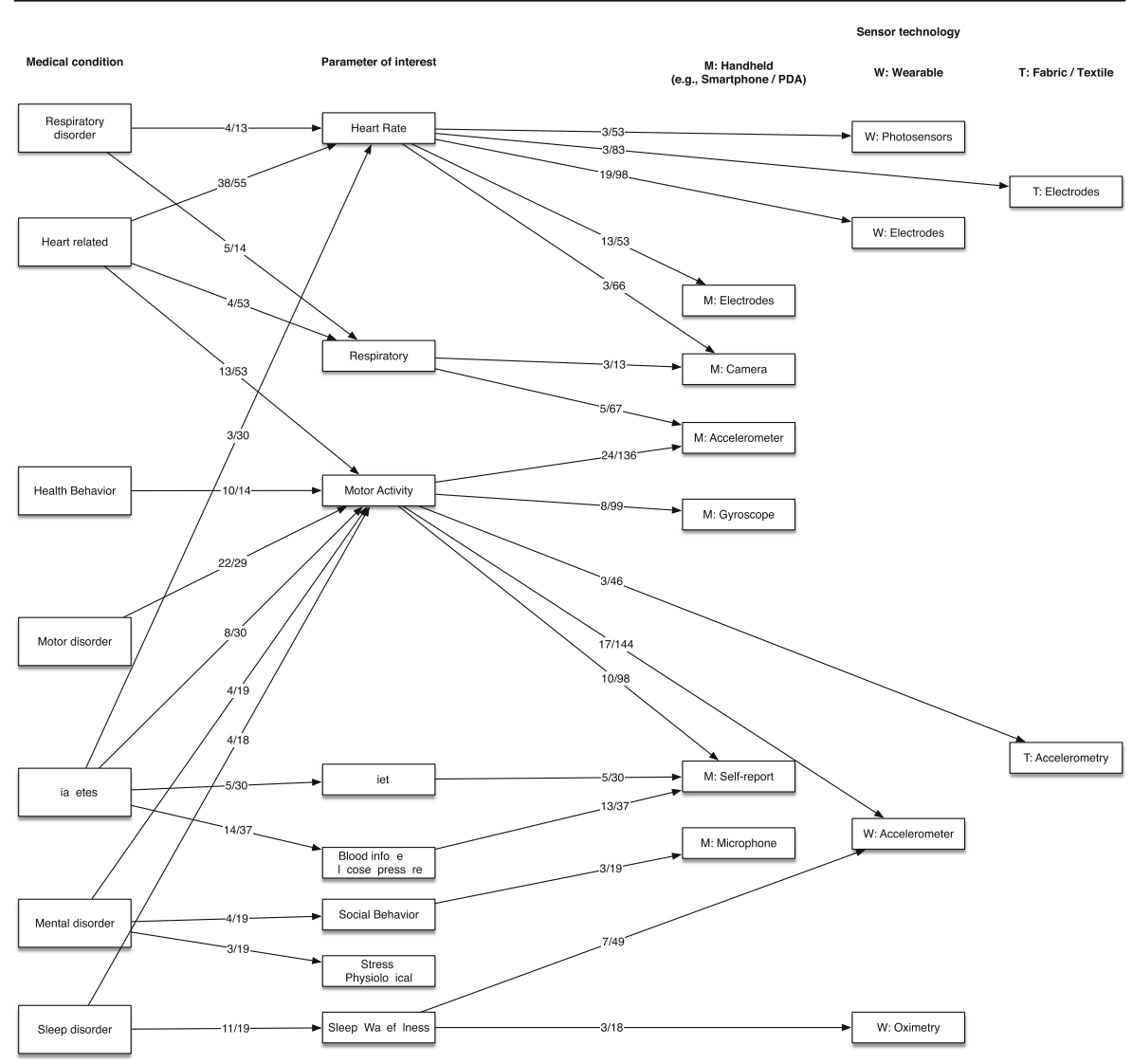

Fig. 9 Taxonomy of sensor technology adopted in research studies to provide detection and monitoring of diseases-related characteristics/parameter of interest. For example, according to this review, a heart rate can be monitored from different perspectives such as photosensors (wearables), electrodes (mobile/wearable/textile), and cameras sensing (mobile).

Although there is a tendency towards mobile and wearable technology, textile solutions are increasing with the increasing use of electrodes and accelerometer sensing. Textile-related projects include the development of adhesive patches that can be worn by users more comfortably; they are usually the actuator of a system in which a smartphone plays the role of a hub to collate and display data $[116,122,123]$. Connectivity is possible using wireless technology, thus increasing users' comfort. Tight-fitting clothes and accessories like gloves and forearm bands enable extended monitoring and a non-intrusive experience.

\subsection{Application to Healthcare}

The technological application includes behavioural pattern discovery for disease prevention, prediction, and treatment support based on monitoring services. Figure 10 illustrates how heart disorders, followed by wellbeing, are the areas in which most studies have focused ( $30 \%$ and $15 \%$, respectively). The below results omit those cases representing less than $1 \%$ of articles; these include projects related to eating disorder 
[28, 220], cystic fibrosis [221], dehydration [115, 175], dyskinesia, drug-induced [54], health behaviour [108, 121,133,149, 156, 192], musculoskeletal diseases [182], neoplasms [26], obesity [107, 111, 186, 222], peripheral arterial disease [40], ulcer [116], and vision disorder [141].

Heart Disorders This category represents $26.72 \%$ of articles that focus on cardiovascular health. According to the 2017 statistics from the World Health Organization (WHO), heart attacks and strokes cause up to $31 \%$ of deaths globally (i.e. 17.7 million people every year). Global heart initiatives are being economically supported in order to prevent and manage heart rate conditions as part of primary healthcare [223]. Electrocardiogram data is adopted in current healthcare applications due to its advancements in the physiological monitoring of everyday activities. Studies have demonstrated the feasibility of building passive modules using near-field communication (NFC) devices carried on mobile phones [130]. Others have introduced garments (i.e. brassiere-based) with reliable measurements of up to $89.53 \%$ of signals detected and overall user acceptability [123]. From conductive fabric and electrode bands to fabric woven from silver-coated yarn, textile developments are incorporating custom-designed and flexible electrodes to improve practical adoptions in daily situations [224]. The overall aim of the related works is to detect cardiac malfunctions so that family and clinicians are notified and may be able to take some actions that would benefit the patient. They focus on non-intrusive and non-clinical environmental conditions, and a long-term analysis is envisaged in order to produce records for a better understanding of irregular signal patterns.

General Healthcare This section includes studies about technologies to improve wellness [84], mobility monitoring [150], eating behaviour [158], and sedentary behaviour [167], among others. For example, J. Choi et al. [188] propose a service for monitoring personal health states by using smart device-based data extraction and health life ontology modelling using health lifelog analysis. Y. Zhang et al. [148] propose the creation of a remote mobile health monitor system and web service capable of

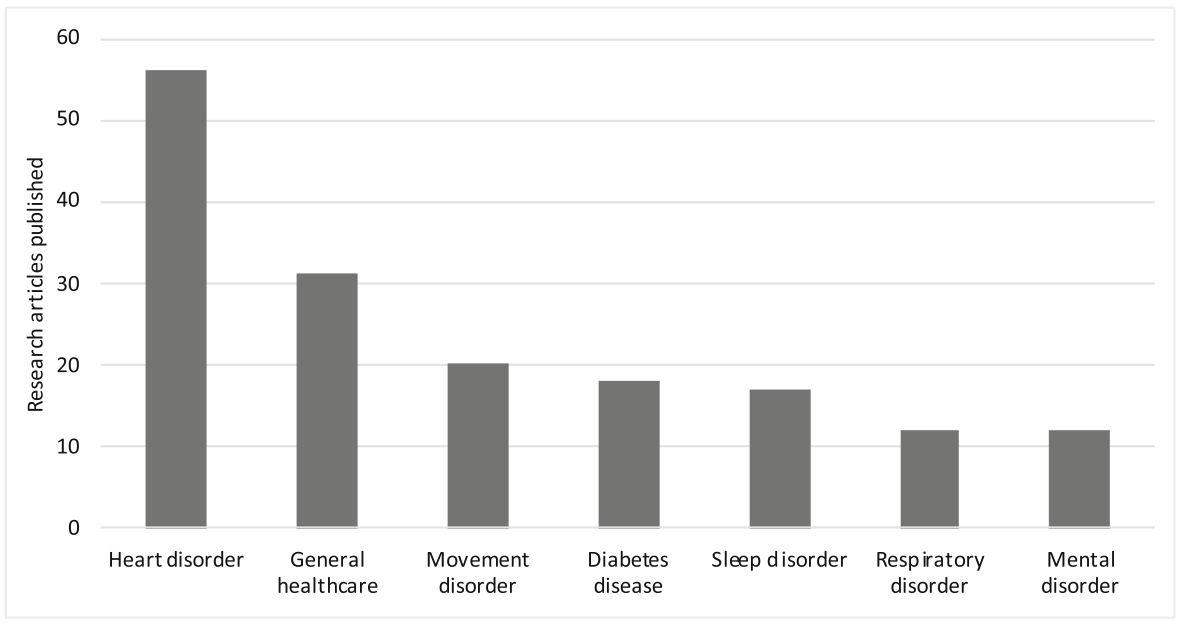

Fig. 10 The number of studies per health condition/disorder. 
providing a comprehensive health solution. It can provide doctors and family members with a secure mechanism for remote diagnosis and supports real-time alerts during urgent situations. Their research comprises $14.28 \%$ of the articles in this review. Overall, previous works' results show the reliability of monitoring wellness and physiologic parameters associated with patients' health.

Movement Disorder This category includes a wide variety of articles based on motor characteristics such as rigidity, tremor, bradykinesia, hypokinesia, posture, motion control, and similar. It consists of $9.21 \%$ of the articles. Medical application varies from gait analysis [119], measuring anticipatory posture towards personalised healthcare [97], epilepsy prediction [172], fall detection systems and algorithms [65], and general activity recognition [174]. For instance, N. Kostikis et al. [131] propose a held or mounted smartphone-based application to assess limb tremor in patients with Parkinson's disease. The examples mentioned above use accelerometers, gyroscopes, and magnetometers, all of which can be micro-electro-mechanical and, when combined, can detect intricate movement patterns. Overall, discussion of device implementation focuses on the devices being low cost, energy efficient, platform-independent, non-intrusive, and requiring no specialised expertise (due to its opportunistic approach). These discussions envision easy clinical examination that happens while patients conduct their daily activities.

Diabetes Disease This category represents $8.29 \%$ of the articles. It involves articles that elaborate on glucose monitoring. In general, patients can benefit from sporadic or continuous blood monitoring in order to receive a proper insulin dose. Technological progress is driven towards a self-management approach by integrating wireless features into insulin pumps and analysing the gathered data to build predictive models. Feasible studies suggest that smartwatches and mobile phones could be used as stand-alone devices to continuously monitor sugar levels, insulin injections, physical activity, and dietary information [151]. A theoretical study addresses prototyping systems to selfadminister insulin based on statistical models to improve the patient experience [132]. A study on glucose monitoring adherence using smartwatches was investigated in a young population, and it was demonstrated that participatory monitoring behaviour in adolescents is likely to be affected by social context due to the interruption of daily activities and the users' desire to blend in with their peers [109]. In this regard, technological progress is being made by evaluating the user acceptance of wearable devices to monitor vital signs and by building more transparent technology (i.e. nonintrusive and low cognitive demanded) in terms of product design towards friendly use adoption.

Sleep Disorder This category focuses on research addressing quality of sleep, representing up to $7.83 \%$ of articles from this scoping review. Disorders such as obstructive sleep apnoea (OSA) are regarded as significant risk factors for diseases that can lead to serious health problems [85]. Snoring is a sign of increased airway resistance and is reported to be a common symptom for OSA. Koo SK et al. [173] recorded snoring sounds according to the obstruction level using a smartphone and focused on the analysis of formant frequencies. They found that spectrographic analysis indicates that retropalatal level obstruction tended to produce sharp and regular peaks. 
In contrast, retro-lingual level obstruction tended to show peaks with a gradual onset and decay, giving medical practitioners the ability to analyse snoring in a non-intrusive manner. Garde A. et al. [145] presents a validation in which a phone oximeter is compared against polysomnography, the gold standard for OSA diagnosis, which is resource-intensive and requires a specialised laboratory. The increasing demands for home-based sleep monitoring have prompted the development of devices that monitor sleep using fewer sensors. Other approaches use acceleration and angular velocity obtained from built-in smartphone sensors and then applied a wavelet denoising technique to minimise the nonstationary noise [117].

Respiratory Disorders This section represents $5.52 \%$ of articles that elaborate on aspects of human ventilation, particularly pulmonary-related. Patients suffering from dyspnoea, chronic obstructive pulmonary disease, or asthma can be monitored for early detection of symptoms and the administration of treatments after hospital interventions. In this regard, the convergent validity of accelerometer and self-reported activity data have been presented as evidence of the feasibility of assessing the respiratory condition in different populations. For example, in children diagnosed with asthma [87], patients with chronic obstructive pulmonary disease [29, 179], and healthy subjects [142] (in which findings report from moderate to high), there is an agreement between estimates of exertion made using sensor data and those reported by participants. Other examples include Il Hyung et al., who present a study conducted in early 2007 in which they monitor oxygen saturation by using the Sp02 module sensor. They combine data with electrocardiography (ECG) and a global positioning system (GPS) to illustrate the geographic walking routes in which users experienced the highest demand of oxygen [60]. Under a more non-intrusive mechanism, N. Hernández and J. Favela [225] propose a model and mobile application to identify elderly physical fatigue based on a correlation between heart rate, oxygen consumed, and physical fatigue perceived by participants.

Mental Disorder This section represents $5.52 \%$ of the articles. It includes application of psychosomatic research for diagnoses such as schizophrenia [102], bipolar disorder [27], ruminative self-focus [25], emotional monitoring [160], and social rhythms [185], among others. Although some projects rely on self-report mechanisms, [194], automatic solutions are more common in recent years. Efforts included the Electronically Activated Recorder (EAR), which consists of periodical audio recordings that nonintrusively record snippets of ambient sounds from users' environments [101]. An audio sensor has also been used for detecting bipolar disorder, yielding acoustic logs of people's day-to-day activities as they naturally unfold. For instance, A. Guidi et al. [155] developed an Android application for analysing speech while using a smartphone device. Their results demonstrated that speech frequency could be reliably estimated, thus describing prosodic features across the audio sample.

Overall, those articles representing less than $1 \%$ of the contribution involve the design and development of studies and projects associated with the identification of health-related patient characteristics that could further be addressed by particular disease monitoring. Characteristics include (but are not limited to) weight loss [186], temperature [199], oncology practices [26], dynamic compression [182], and body mass index [192]. Moreover, platform designs and software frameworks are also taken 
into account [121]. For instance, Becher K. et al. [67] describe a wireless sensor gateway that allows recording of bio-signals such as electrocardiogram, pulse wave, and body weight. It has the distinctive feature of using two different radio transceivers, exploiting the advantages of technology for constant monitoring. More non-intrusive approaches are being developed; Chung P. et al. [116] propose the use of a Bluetoothenabled fabric-based pressure sensor array to assess and continuously monitor decubitus ulcer risk. Although this particular project is still only implemented as a prototype, their invention could positively affect mobile healthcare applications.

\section{Discussion}

Traditional medicine diagnoses, clinical interventions, and rehabilitation treatments require patients to be monitored over time, which tends to be cumbersome and expensive. MWT technology opens the possibility of using sensor technology to build solutions for the prevention of disease through continuous monitoring. This scoping review examines how MWT technology has been improving healthcare by offering alternate solutions to challenging issues based on non-intrusive patient monitoring.

Overall findings in this review demonstrate that using mobile and wearable devices for automatic monitoring of mental behaviour is a feasible approach and a key marker of wellbeing for monitoring individuals with health conditions. Moreover, due to approximately $90 \%$ of our bodies typically being covered by clothing, the use of smart garments is promising [131]. By using mobile technology, the analysis of sensor data can be a useful screening test for the prediction of occlusion on a daily basis.

Publication Trends Some of the figures reflect a stark increase of publications in some years, notably in 2016 and 2017. There are some plausible explanations for these spikes. For instance, the Apple Watch was launched in 2015, which could have attracted attention to commercial gadgets. Also, consumer electronics and research technology could be more mature by the time of publication. PubMed does not typically index conferences, where much of the work-in-progress research could have been published.

The Technology Used For this study, it can be argued that wearable devices (e.g. physical activity trackers, smartwatches) have a low level of intrusiveness since they are expected to be worn rather than carried by the user (as is the case with most studies involving mobile devices used for monitoring purposes). Setting restrictions have been discussed in different articles [226], indicating that results and interpretation outcomes are likely to vary depending on the device's physical orientation and location.

Participatory vs Opportunistic Sensing Due to the rapid adoption and availability of off-the-shelf technology, smartphones started to be conceived as tools to capture information (as reported by the $80 \%$ of the article considered in this study). The year of 2007 represents the beginning of building databases based on associating activity performance with sensor data by using the labelling approach, where users were mostly asked to enable data recording while carrying sensing devices. Similarly, other studies 
required users to manually capture self-assessment measurements [69-72]. Still, it can be seen that the in the case of smartphone-based studies, a great percentage use the participatory sensing approach. This can be explained by the nature of the device, having sensing capabilities as well as ways to provide feedback (e.g. keyboard and display). Along these lines, this can also explain why wearable-based studies focus on using the opportunistic sensing approach, as many of these gadgets are mainly worn to collect data from specific parts of the body (e.g. legs) or because it is conventional (e.g. wristwatch).

Research Evaluation Evaluation is maturing in different ways. For instance, $68.01 \%$ $(n=151)$ of articles found in this scoping review consist of prototyping $(n=103)$ and proof of concept for research purposes $(n=48)$, whereas $18.46 \% \quad(n=41)$ corresponds to commercial systems, and $5.40 \%(n=12)$ to devices' clinical approval. Similarly, considering that the strength of evidence is stronger in quantitative research, particularly concerning RCT, results from this scoping review show that since 2014 the percentage of studies conducting RTC $(n=28)$ has doubled compared to qualitative studies $(n=12)$. The doubling can be explained by the relative length of time that it can take to plan, execute, and publish an RTC study, as compared to other types of studies. Also, the increase of other types of studies (such as quantitative) may be the result of technology advancement, as mentioned in the previous paragraphs.

Sensor Technology The concept of computing is rapidly expanding from using desktop computers to portable computation devices that have sensors and access to a network. Traditional sensor capabilities consist of detecting sounds, images, body motion, or ambient light level. However, advances in technology are quickly evolving. Embedded sensors can now transmit biochemical (glucose, chemistries) and physiological (skin temperature, electroencephalogram, blood pressure, blood oxygen saturation, respiration rate heart rate, electrocardiogram, cardiac output, and weight) information from the user as it is carried or worn, with information sent to remote processing units. Sensors are becoming so small and flexible that they are unobtrusive; either woven into clothing or laminated onto ultrathin skin interfaces and placed on the human body. As more sensors become available, there will be more studies on possible uses. Perhaps much more important, as more consumer electronics or digital health devices are cleared by the FDA, we can expect more studies that can include them in RCT studies.

\subsection{Reflections for Future Research}

As we read through the literature included in this study, we observed that their qualitative findings reported comparable practices across the computing technology, medical informatics, and engineering disciplines when building solutions for monitoring health. Since the majority of the contributions consisted of prototypes and early implementations, we believe that reporting such insights would be particularly valuable to our community by accelerating the development of emerging prototypes into operational pieces of technology. Our observations can be summarised into four guidelines: 
Unobtrusive Approach to Data Gathering Given the wide variety and accessibility to MWT sensing devices, one's technology selection should be aligned with the user's acceptability. As reflected by the articles reviewed, one approach is the adoption of unobtrusive monitoring, where the sensing devices are worn/carried by the user without interrupting their normal activities. By using this approach, medical professionals could monitor patients in real time and during more extended periods than those that are possible during a hospital stay or a visit to a physician's office. These systems could then provide real-time processing and feedback to medical staff, patients, athletes, and even issue alerts in the event of an emergency.

Creative Use of Sensing Technology Each piece of sensing technology brings particular characteristics to the sensed data, so one should have a creative mindset when developing products that provide the clinical information required (parameter of interest) without compromising the comfort of wearing/carrying the sensing devices. When the revised articles were organised over application topics across the sensing technology, they revealed how creativity is an essential attribute when building monitoring technology. In Fig. 9, we can see how sensing technology from different feature spaces is utilised to build solutions yielding a similar parameter of interest regardless of wireless communication constraints, processing capabilities, power supplies, storage capacity, or physical dimensions.

Evidence Supported by Clinical Practices One should focus on conducting robust evaluations to produce high-level, credible evidence [227]. A randomised controlled trial [228] is a standard clinical practice recently adopted by the engineering community. RCTs can reduce certain sources of biases, thereby increasing the influence results have upon the stakeholder (e.g. regulators, practitioner, patients, federal organisations) [229].

User-Centred Design The explicit understanding of the end user is essential when developing a useful and usable piece of technology [230]. As observed across the reviewed articles of this study, conducting user-centred examinations at the design stage contributes insights that will facilitate acceptability, engagement, and usability. This approach can accelerate the deployment and adoption of novel technology while developing effective pieces of computational technology to continuously monitor health.

\section{Conclusion}

Health-related needs are changing, and people want to be more involved in the management of their health, preferring painless methods of diagnosis and treatments. In this regard, there is a trend towards effortless and painless methods of diagnosis and treatment moving from traditional institution-centred care towards a patient, citizencentred one. The ubiquity of information technology and the increase of computational capabilities open opportunities for continuous health monitoring systems by wearing or carrying day-to-day devices such as smartphones, smartwatches, smart clothing, and 
fitness trackers. In this study, we present the current literature on how mobile, wearable, and textile sensing technology has influenced the medical field by bringing technological solutions to problems in which continuous monitoring is essential.

This scoping review follows the PRISMA review protocol. We present an overview of 222 articles retrieved from PubMed. Of these, 101 articles (45.5\%) have been published in medical journals, 60 articles $(27 \%)$ were published in multidisciplinary journals and 41 articles (18.5\%) in proceedings, while 14 articles $(6 \%)$ were published in engineering journals and 6 articles $(3 \%)$ were published in proceedings. Although most of the studies reviewed used quantitative methodologies, results show an escalation in the number of articles adopting standardised clinical methodologies such as RCTs (currently rating to $13.5 \%$ ). With regard to the technology and data collection approach, a majority of the participatory sensing approach studies rely on mobile devices such as smartphones (77\%), with a contrasting interest in the adoption of opportunistic data collection approach when using wearable sensing technology (91\%).

Acknowledgments Dr Mortenson's work was supported by a New Investigator Award from the Canadian Institutes of Health Research.

\section{REFERENCES}

1. Dawood FS et al (2012) Estimated global mortality associated with the first 12 months of 2009 pandemic influenza A H1N1 virus circulation: A modelling study. Lancet Infect Dis. https://doi.org/ 10.1016/S1473-3099(12)70121-4

2. Den Boon S et al (2019) Ebola virus infection associated with transmission from survivors. Emerg Infect Dis. https://doi.org/10.3201/eid2502.181011

3. Gastañaduy PA et al (2018) Public health responses during measles outbreaks in elimination settings: Strategies and challenges. Human Vacc Immunotherapeutics. https://doi.org/10.1080/21645515.2018. 1474310

4. Ganeshkumar P et al (2018) Dengue infection in India: A systematic review and meta-analysis. PLoS Negl Trop Dis. https://doi.org/10.1371/journal.pntd.0006618

5. Lane ND, Miluzzo E, Lu H, Peebles D, Choudhury T, Campbell AT (2010) A survey of mobile phone sensing. IEEE Commun. Mag. https://doi.org/10.1109/MCOM.2010.5560598

6. Rawassizadeh R, Price BA, Petre M (2015) Wearables: Has the age of smartwatches finally arrived? Commun ACM. https://doi.org/10.1145/2629633

7. Hildebrandt J, Brauner P, Ziefle M (2015) Smart textiles as intuitive and ubiquitous user interfaces for smart homes. In: Lecture notes in computer science (including subseries lecture notes in artificial intelligence and lecture notes in bioinformatics). https://doi.org/10.1007/978-3-319-20913-539

8. University of Cambridge (2011) Mobile communications for medical care

9. Konstantas D, Herzog R (2003) Continuous monitoring of vital constants for mobile users: the MobiHealth approach. Proc 25th Annu Int Conf IEEE Eng Med Biol Soc (IEEE Cat. No.03CH37439). https://doi.org/10.1109/IEMBS.2003.1280970

10. Shuwandy ML, Zaidan BB, Zaidan AA, Albahri AS (2019) Sensor-based mhealth authentication for real-time remote healthcare monitoring system: a multilayer systematic review. J Med Syst. https://doi. org/10.1007/s10916-018-1149-5

11. Cornet VP, Holden RJ (2018) Systematic review of smartphone-based passive sensing for health and wellbeing. J Biomed Inform. https://doi.org/10.1016/j.jbi.2017.12.008

12. Levac D, Colquhoun H, O’Brien KK (2010) Scoping studies: Advancing the methodology. Implement. Sci. https://doi.org/10.1186/1748-5908-5-69

13. Moher D, Liberati A, Tetzlaff J, Altman DG, The PRISMA Group (2009) PRISMA 2009 flow diagram. PLoS Med. https://doi.org/10.1371/journal.pmed1000097

14. Graham E (2016) Improving outcomes through personalised medicine. NHS Engl 
15. Lee H, Chen YPP (2015) Image based computer aided diagnosis system for cancer detection. Exp Syst Appl. https://doi.org/10.1016/j.eswa.2015.02.005

16. Syed Umar Amin KA, Beg R (2013) Data mining in clinical decision support systems for diagnosis, prediction and treatment of heart disease. Int J Adv Res Comput Eng Technol

17. Merians AS et al (2002) Virtual reality-augmented rehabilitation for patients following stroke. Phys. Ther. https://doi.org/10.1093/ptj/82.9.898

18. Neumann PJ, Claxton K, Weinstein MC (2000) The FDA's regulation of health economic information. Health Aff. https://doi.org/10.1377/hltha.19.5.129

19. Comstock J (2017) Apple, Stanford launch Apple Heart Study to improve atrial fibrillation detection. Mobile Health News

20. N.A (2017) Apple is going after the health care industry, starting with personal health data. CB Insights

21. Drott MC (1995) Reexamining the role of conference papers in scholarly communication. J Am Soc Inf Sci. https://doi.org/10.1002/(SICI)1097-4571(199505)46:4h299::AID-ASI6i3.0.CO;2-0

22. Bryman A (2006) Integrating quantitative and qualitative research: How is it done? Qual Res. https:// doi.org/10.1177/1468794106058877

23. Sevick MA et al (2008) Design, feasibility, and acceptability of an intervention using personal digital assistant-based self-monitoring in managing type 2 diabetes. Contemp Clin Trials 29:396-409. https:// doi.org/10.1016/j.cct.2007.09.004

24. Magnan RE, Köblitz AR, McCaul KD, Dillard AJ (2013) Self-monitoring effects of ecological momentary assessment on smokers' perceived risk and worry. Psychol Assess. https://doi.org/10. 1037/a0031232

25. Takano K, Sakamoto S, Tanno Y (2013) Ruminative self-focus in daily life: Associations with daily activities and depressive symptoms. Emotion. https://doi.org/10.1037/a0031867

26. Blum D et al (2014) Feasibility and acceptance of electronic monitoring of symptoms and syndromes using a handheld computer in patients with advanced cancer in daily oncology practice. Support Care Cancer. https://doi.org/10.1007/s00520-014-2201-8

27. Faurholt-Jepsen M, Vinberg M, Frost M, Christensen EM, Bardram JE, Kessing LV (2015) Smartphone data as an electronic biomarker of illness activity in bipolar disorder. Bipolar Disord. https://doi.org/10. 1111/bdi. 12332

28. Kropff $\mathbf{J}$ et al (2015) 2 month evening and night closed-loop glucose control in patients with type 1 diabetes under free-living conditions: A randomised crossover trial. Lancet Diabetes Endocrinol. https:// doi.org/10.1016/S2213-8587(15)00335-6

29. Verwey R, van der Weegen S, Spreeuwenberg M, Tange H, van der Weijden T, de Witte L (2016) Process evaluation of physical activity counselling with and without the use of mobile technology: A mixed methods study. Int J Nurs Stud. https://doi.org/10.1016/j.ijnurstu.2015.10.008

30. Zhou W, Chen M, Yuan J, Sun Y (2016) Welltang - A smart phone-based diabetes management application - Improves blood glucose control in Chinese people with diabetes. Diabetes Res Clin Pract. https://doi.org/10.1016/j.diabres.2016.03.018

31. Padhye NS, Wang J (2015) Pattern of active and inactive sequences of diabetes self-monitoring in mobile phone and paper diary users. In: Proceedings of the Annual International Conference of the IEEE Engineering in Medicine and Biology Society, EMBS. https://doi.org/10.1109/IEMBS.2007. 4352782

32. Mackillop LH et al (2016) Trial protocol to compare the efficacy of a smartphone-based blood glucose management system with standard clinic care in the gestational diabetic population. BMJ Open. https:// doi.org/10.1136/bmjopen-2015-009702

33. Vorrink SNW, Kort HSM, Troosters T, Zanen P, Lammers JWJ (2016) Efficacy of an mHealth intervention to stimulate physical activity in COPD patients after pulmonary rehabilitation. Eur Respir J. https://doi.org/10.1183/13993003.00083-2016

34. Grønli J, Byrkjedal IK, Bjorvatn B, Nødtvedt O, Hamre B, Pallesen S (2016) Reading from an iPad or from a book in bed: The impact on human sleep. A randomized controlled crossover trial. Sleep Med. https://doi.org/10.1016/j.sleep.2016.02.006

35. Rångtell FH et al (2016) Two hours of evening reading on a self-luminous tablet vs. reading a physical book does not alter sleep after daytime bright light exposure. Sleep Med. https://doi.org/10.1016/j.sleep. 2016.06.016

36. Takahashi PY, Quigg SM, Croghan IT, Schroeder DR, Ebbert JO (2016) Effect of pedometer use and goal setting on walking and functional status in overweight adults with multimorbidity: A crossover clinical trial. Clin Interv Aging. https://doi.org/10.2147/CIA.S107626

37. Skobel E et al (2017) Internet-based training of coronary artery patients: The heart cycle trial. Heart Vessels. https://doi.org/10.1007/s00380-016-0897-8 
38. Brakenridge CL et al (2016) Evaluating the effectiveness of organisational-level strategies with or without an activity tracker to reduce office workers' sitting time: A cluster-randomised trial. Int J Behav Nutr Phys Act. https://doi.org/10.1186/s12966-016-0441-3

39. Velardo C et al (2017) Digital health system for personalised COPD long-term management. BMC Med Inform Decis Mak. https://doi.org/10.1016/j.ifacol.2016.03.038

40. Gardner AW et al (2017) Association between daily walking and antioxidant capacity in patients with symptomatic peripheral artery disease. J Vasc Surg. https://doi.org/10.1017/S0950268818001115

41. Van Stan JH, Mehta DD, Sternad D, Petit R, Hillman RE (2017) Ambulatory voice biofeedback: relative frequency and summary feedback effects on performance and retention of reduced vocal intensity in the daily lives of participants with normal voices. J Speech Lang Hear Res. https://doi. org/10.1044/2016JSLHR-S-16-0164

42. Halcox JPJ et al (2017) Assessment of remote heart rhythm sampling using the AliveCor heart monitor to screen for atrial fibrillation the REHEARSE-AF study. Circulation. https://doi.org/10.1161/ CIRCULATIONAHA.117.030583

43. Kwon S et al. (2016) Sinabro: A smartphone-integrated opportunistic electrocardiogram monitoring system. Sensors (Switzerland). https://doi.org/10.3390/s16030361

44. Whelan ME, Kingsnorth AP, Orme MW, Sherar LB, Esliger DW (2017) Sensing interstitial glucose to nudge active lifestyles (SIGNAL): Feasibility of combining novel self-monitoring technologies for persuasive behaviour change. BMJ Open. https://doi.org/10.1136/bmjopen-2017-018282

45. Onoue $\mathrm{T}$ et al (2017) Randomized controlled trial for assessment of Internet of Things system to guide intensive glucose control in diabetes outpatients: Nagoya Health Navigator Study protocol. Nagoya J Med Sci. https://doi.org/10.18999/nagjms.79.3.323

46. Nogic J, Thein PM, Cameron J, Mirzaee S, Ihdayhid A, Nasis A (2017) The utility of personal activity trackers (Fitbit Charge 2) on exercise capacity in patients post acute coronary syndrome [UP-STEP ACS Trial]: A randomised controlled trial protocol. BMC Cardiovasc Disord. https://doi.org/10.1186/ s12872-017-0726-8

47. Klee $\mathrm{P}$ et al (2018) an intervention by a patient-designed do-it-yourself mobile device app reduces HbA1c in Children and adolescents with type 1 diabetes: A randomized double-crossover study. Diabetes Technol Ther. https://doi.org/10.1016/j.jadohealth.2012.10.003

48. Gremaud AL et al (2018) Gamifying accelerometer use increases physical activity levels of sedentary office workers. J. Am. Heart Assoc. https://doi.org/10.1161/JAHA.117.007735

49. Wang W et al (2018) A randomized controlled trial on a nurse-led smartphone-based self-management programme for people with poorly controlled type 2 diabetes: A study protocol. J Adv Nurs. https://doi. org/10.1111/jan.13394

50. Rosario MBD et al (2018) Evaluation of an mHealth-Based Adjunct to Outpatient Cardiac Rehabilitation. IEEE J Biomed Heal Informatics. https://doi.org/10.3414/ME9112

51. Goswami U, Black A, Krohn B, Meyers W, Iber C (2019) Smartphone-based delivery of oropharyngeal exercises for treatment of snoring: a randomized controlled trial. Sleep Breath. https://doi.org/10.1007/ s11325-018-1690-y

52. Guo H, Zhang Y, Li P, Zhou P, Chen LM, Li SY (2019) Evaluating the effects of mobile health intervention on weight management, glycemic control and pregnancy outcomes in patients with gestational diabetes mellitus. J Endocrinol Invest. https://doi.org/10.1007/s40618-018-0975-0

53. Burke J et al (2006) Participatory sensing. Work World-Sensor-Web Mob. Device Centric Sens Networks Appl:1-5. https://doi.org/10.1.1.122.3024

54. Moore ST, MacDougall HG, Gracies JM, Cohen HS, Ondo WG (2007) Long-term monitoring of gait in Parkinson's disease. Gait Posture. https://doi.org/10.1016/j.gaitpost.2006.09.011

55. Lee R, Lai C, Chiang S, Liu H, Chen C, Hsieh GDesign and implementation of a mobile-care system over wireless sensor network for home healthcare applications. 2006 International Conference of the IEEE Engineering in Medicine and Biology Society, pp 6004-6007. https://doi.org/10.1109/IEMBS. 2006.259903

56. Nam KW, Lee JJ, Hwang CM, Choi SW, Son HS, Sun K (2007) Personal digital assistant-based, internet-enabled remote communication system for a wearable pneumatic biventricular assist device. Artif Organs 31:842-845. https://doi.org/10.1111/j.1525-1594.2007.00475.x

57. Kim JM, Hong JH, Cho MC, Cha EJ, Lee TS (2007) Wireless biomedical signal monitoring device on wheelchair using noncontact electro-mechanical film sensor. In: Annual International Conference of the IEEE Engineering in Medicine and Biology - Proceedings. https://doi.org/10.1109/IEMBS.2007. 4352355 
58. Lee TS, Hong JH, Cho MC (2007) Biomedical digital assistant for ubiquitous healthcare. In: Annual International Conference of the IEEE Engineering in Medicine and Biology - Proceedings. https://doi. org/10.1109/IEMBS.2007.4352659

59. Kyriacou E et al (2007) An m-health monitoring system for children with suspected arrhythmias. In: Annual International Conference of the IEEE Engineering in Medicine and Biology - Proceedings. https://doi.org/10.1109/IEMBS.2007.4352660

60. Shin IH, Lee JH, Kim HC (2007) Ubiquitous monitoring system for chronic obstructive pulmonary disease and heart disease patients. In: 2007 29th Annual International Conference of the IEEE Engineering in Medicine and Biology Society, pp 3689-3692. https://oi.org/10.1109/IEMBS.2007. 4353132

61. Sneha S, Varshney U (2007) A wireless ECG monitoring system for pervasive healthcare. Int J Electron Healthc. https://doi.org/10.1504/IJEH.2007.011479

62. Arsand E, Olsen O-A, Varmedal R, Mortensen W, Hartvigsen G (2008) A system for monitoring physical activity data among people with type 2 diabetes. Stud Health Technol Inform

63. Curtis D et al (2007) Is redundancy in vital signs monitoring useful? AMIA Annu Symp Proc

64. Bickmore T, Gruber A, Intille S (2008) Just-in-time automated counseling for physical activity promotion. AMIA Annu Symp Proc

65. Bourke AK, van de Ven PWJ, Chaya AE, OLaighin GM, Nelson J (2008) Testing of a long-term fall detection system incorporated into a custom vest for the elderly. In: 2008 30th Annual International Conference of the IEEE Engineering in Medicine and Biology Society. https://doi.org/10.1109/IEMBS. 2008.4649795

66. D'Angelo LT, Czabke A, Somlai I, Niazmand K, Lueth TC (2010) ART - A new concept for an activity recorder and transceiver. In: 2010 Annual International Conference of the IEEE Engineering in Medicine and Biology Society, EMBC'10. https://doi.org/10.1109/IEMBS.2010.5627262

67. Becher K, Figueiredo CP, Mühle C, Ruff R, Mendes PM, Hoffmann KP (2010) Design and realization of a wireless sensor gateway for health monitoring. 2010 Annual International Conference of the IEEE Engineering in Medicine and Biology Society, EMBC'10. https://doi.org/10.1109/IEMBS.2010. 5627996

68. Ong SW et al (2016) Integrating a smartphone-based self-management system into usual care of advanced CKD. Clin J Am Soc Nephrol. https://doi.org/10.2215/CJN.10681015

69. Smith GB et al (2006) Hospital-wide physiological surveillance-A new approach to the early identification and management of the sick patient. Resuscitation. https://doi.org/10.1016/j.resuscitation.2006. 03.008

70. Killeen JP, Chan TC, Buono C, Griswold WG, Lenert LA (2006) A wireless first responder handheld device for rapid triage, patient assessment and documentation during mass casualty incidents. Proc AMIA Annu Symp

71. Crawford D, Gao T, White D (2006) Information collection and dissemination: toward a portable, realtime information sharing platform for emergency response. AMIA Annu Symp Proc

72. Struzik ZR et al (2007) 'Mobile nurse' platform for ubiquitous medicine. Methods Inf Med

73. Kang DO, Lee HJ, Ko EJ, Kang K, Lee J (2006) A wearable context aware system for ubiquitous healthcare. In: Annual International Conference of the IEEE Engineering in Medicine and Biology Proceedings. https://doi.org/10.1109/IEMBS.2006.259538

74. José $\mathrm{AB}$ et al (2007) A framework for automated evidence gathering with mobile systems using bayesian networks. In: Annual International Conference of the IEEE Engineering in Medicine and Biology - Proceedings. https://doi.org/10.1109/IEMBS.2007.4353130

75. Sufi F, Fang Q, Cosic I (2007) ECG R-R peak detection on mobile phones. In: Annual International Conference of the IEEE Engineering in Medicine and Biology - Proceedings. https://oi.org/10.1109/ IEMBS.2007.4353134

76. Quero JM et al (2007) Health care applications based on mobile phone centric smart sensor network. In: Annual International Conference of the IEEE Engineering in Medicine and Biology - Proceedings. https://doi.org/10.1109/IEMBS.2007.4353795

77. Baldwin LP, Low PH, Picton C, Young T (2007) The use of mobile devices for information sharing in a technology-supported model of care in A\&E. Int J Electron Healthc 3(1):90. https://doi.org/10.1504/ ijeh.2007.011482

78. Lucani D, Cataldo G, Cruz J, Villegas G, Wong S (2006) A portable ECG monitoring device with Bluetooth and Holter capabilities for telemedicine applications. In: Annual International Conference of the IEEE Engineering in Medicine and Biology - Proceedings. https://doi.org/10.1109/IEMBS.2006. 260798 
79. Goh KW, Kim E, Lavanya J, Kim Y, Soh CB (2006) Issues in implementing a knowledge-based ECG Analyzer for personal mobile health monitoring. In: Annual International Conference of the IEEE Engineering in Medicine and Biology - Proceedings. https://doi.org/10.1109/IEMBS.2006.259632

80. Ahola T, Korpinen P, Rakkola J, Rämö T, Salminen J, Savolainen J (2007) Wearable FPGA based wireless sensor platform. In: Annual International Conference of the IEEE Engineering in Medicine and Biology - Proceedings. https://doi.org/10.1109/IEMBS.2007.4352782

81. Bidargaddi NP, Sarela A (2008) Activity and heart rate-based measures for outpatient cardiac rehabilitation. Methods Inf. Med. https://doi.org/10.3414/ME9112

82. Dalton AF, Scanaill CN, Carew S, Lyons D, Ólaighin G (2007) A clinical evaluation of a remote mobility monitoring system based on SMS messaging. In: Annual International Conference of the IEEE Engineering in Medicine and Biology - Proceedings. https://doi.org/10.1109/IEMBS.2007.4352792

83. Johnson EI, Barrault M, Nadeau L, Swendsen J (2009) Feasibility and validity of computerized ambulatory monitoring in drug-dependent women. Drug Alcohol Depend. https://doi.org/10.1016/j. drugalcdep.2008.06.010

84. Ahtinen A, Mantyjarvi J, Hakkila J (2008) Using heart rate monitors for personal wellness - The user experience perspective. In: 2008 30th Annual International Conference of the IEEE Engineering in Medicine and Biology Society. https://doi.org/10.1109/IEMBS.2008.4649476

85. Chang K-M (2009) Portable obstructive sleep apnea screening system using overnight ECG and a PDAbased wireless transmission system. Telemed. e-Health. https://doi.org/10.1089/tmj.2008.0142

86. Schrama T (2009) A wireless portable physiology recorder for psychophysiology research based on a personal digital assistant. Behav Res Methods. https://doi.org/10.3758/BRM.41.3.827

87. Floro JN, Dunton GF, Delfino RJ (2009) Assessing physical activity in children with asthma: Convergent validity between accelerometer and electronic diary data. Res Q Exerc Sport. https:/doi. org/10.1080/02701367.2009.10599549

88. Nimmala VSR, Penders J, van Hyfte D, Brands M, Gyselinckx B (2008) Semantic wireless body area networks. In: 2008 30th Annual International Conference of the IEEE Engineering in Medicine and Biology Society. https://doi.org/10.1109/IEMBS.2008.4649938

89. Yang H-K et al (2008) Application for the wearable heart activity monitoring system : Analysis of the autonomic function of HRV. In: 2008 30th Annual International Conference of the IEEE Engineering in Medicine and Biology Society

90. Soltani MA (2009) Integrating a hand held computer and stethoscope into a fetal monitor. Med Educ Online. https://doi.org/10.3885/meo.2009.T0000135

91. Hachizuka M et al (2010) Development of a Personal Digital Assistant (PDA) System to collect symptom information from home hospice patients. J Palliat Med. https://doi.org/10.1089/jpm.2009. 0350

92. Pärkkä J, Cluitmans L, Ermes M (2010) Personalization algorithm for real-time activity recognition using PDA, wireless motion bands, and binary decision tree. IEEE Trans Inf Technol Biomed. https:// doi.org/10.1109/TITB.2010.2055060

93. Prajapati SK, Gage WH, Brooks D, Black SE, Mcllroy WE (2011) A novel approach to ambulatory monitoring: Investigation into the quantity and control of everyday walking in patients with subacute stroke. Neurorehabil Neural Repair 25:6-14. https://doi.org/10.1177/1545968310374189

94. Höll B et al (2011) Design of a mobile, safety-critical in-patient glucose management system. In: Studies in Health Technology and Informatics. https://doi.org/10.3233/978-1-60750-806-9-950

95. Schwerdtfeger A, Eberhardt R, Chmitorz A, Schaller E (2010) Momentary affect predicts bodily movement in daily life: An ambulatory monitoring study. J Sport Exerc Psychol. https://doi.org/10. 1123/jsep.32.5.674

96. Miranda-Cid A, Alvarado-Serrano C (2010) An ECG ambulatory system with mobile embedded architecture for ST-segment analysis. 2010 Annual International Conference of the IEEE Engineering in Medicine and Biology Society, EMBC'10. https://doi.org/10.1109/IEMBS.2010.5626165

97. Rigoberto MM, Toshiyo T, Masaki S (2010) Smart phone as a tool for measuring anticipatory postural adjustments in healthy subjects, a step toward more personalized healthcare. In: 2010 Annual International Conference of the IEEE Engineering in Medicine and Biology Society, EMBC'10. https://doi.org/10.1109/IEMBS.2010.5626162

98. Gargiulo G, Bifulco P, Cesarelli M, Jin C, McEwan A, Van Schaik A (2010) Wearable dry sensors with bluetooth connection for use in remote patient monitoring systems. In: Studies in Health Technology and Informatics. https://doi.org/10.3233/978-1-60750-659-1-57

99. Angelidis PA (2010) Personalised physical exercise regime for chronic patients through a wearable ICT platform. Int J Electron Healthc. https://doi.org/10.1504/IJEH.2010.036207 
100. D'Angelo LT, Schneider M, Neugebauer P, Lueth TC (2011) A sensor network to iPhone interface separating continuous and sporadic processes in mobile telemedicine. In: Proceedings of the Annual International Conference of the IEEE Engineering in Medicine and Biology Society, EMBS. https://oi. org/10.1007/s10994-008-5060-Z

101. Mehl MR, Robbins ML, Deters FG (2012) Naturalistic observation of health-relevant social processes: The electronically activated recorder methodology in psychosomatics. Psychosom Med. https://doi.org/ 10.1097/PSY.0b013e3182545470

102. Ben-Zeev D, McHugo GJ, Xie H, Dobbins K, Young MA (2012) Comparing retrospective reports to real-time/real-place mobile assessments in individuals with schizophrenia and a nonclinical comparison group. Schizophr Bull. https://doi.org/10.1093/schbul/sbr171

103. Lee M, Gatton TM, Lee KK (2010) A monitoring and advisory system for diabetes patient management using a rule-based method and KNN. Sensors

104. Kim J, Huo X, Minocha J, Holbrook J, Laumann A, Ghovanloo M (2012) Evaluation of a smartphone platform as a wireless interface between tongue drive system and electric-powered wheelchairs. IEEE Trans Biomed Eng. https://doi.org/10.1109/TBME.2012.2194713

105. Pollonini L, Rajan NO, Xu S, Madala S, Dacso CC (2012) A novel handheld device for use in remote patient monitoring of heart failure patients-design and preliminary validation on healthy subjects. J Med Syst. https://doi.org/10.1007/s10916-010-9531-y

106. Leone JR (2011) Utility of a wireless, handheld monitoring system in the management of hemophilia patients. CIN - Comput Informatics Nurs. https://doi.org/10.1097/NCN.0b013e3182066356

107. Päler S, Wolff M, Fischer WJ (2012) Food intake monitoring: An acoustical approach to automated food intake activity detection and classification of consumed food. Physiol Meas. https://doi.org/10. 1088/0967-3334/33/6/1073

108. Vankipuram M, McMahon S, Fleury J (2012) ReadySteady: app for accelerometer-based activity monitoring and wellness-motivation feedback system for older adults. AMIA Annu Symp Proc

109. Borus JS, Blood E, Volkening LK, Laffel L, Shrier LA (2013) Momentary assessment of social context and glucose monitoring adherence in adolescents with type 1 diabetes. J Adolesc Heal. https://doi.org/ 10.1016/j.jadohealth.2012.10.003

110. Saxon LA (2013) Ubiquitous wireless ECG recording: A powerful tool physicians should embrace. J Cardiovasc Electrophysiol. https://doi.org/10.1111/jce.12097

111. Scheers T, Philippaerts R, Lefevre J (2012) Patterns of physical activity and sedentary behavior in normal-weight, overweight and obese adults, as measured with a portable armband device and an electronic diary. Clin Nutr. https://doi.org/10.1016/j.clnu.2012.04.011

112. Vuong AM et al (2012) Factors affecting acceptability and usability of technological approaches to diabetes self-management: a case study. Diabetes Technol Ther. https://doi.org/10.1089/dia.2012.0139

113. Scheers T, Philippaerts R, Lefevre J (2012) Assessment of physical activity and inactivity in multiple domains of daily life: A comparison between a computerized questionnaire and the SenseWear Armband complemented with an electronic diary. Int J Behav Nutr Phys Act. https://oi.org/10.1186/ 1479-5868-9-71

114. Khan MA, Siddiqi MH, Lee SW (2013) Exploratory data analysis of acceleration signals to select lightweight and accurate features for real-time activity recognition on smartphones. Sensors (Switzerland). https://doi.org/10.3390/s131013099

115. Peterson SK et al (2013) Identifying early dehydration risk with home-based sensors during radiation treatment: A feasibility study on patients with head and neck cancer. J Natl Cancer Inst - Monogr. https://doi.org/10.1093/jncimonographs/lgt016

116. Chung P, Rowe A, Etemadi M, Lee H, Roy S (2013) Fabric-based pressure sensor array for decubitus ulcer monitoring. In: Proceedings of the Annual International Conference of the IEEE Engineering in Medicine and Biology Society, EMBS. https://oi.org/10.1109/EMBC.2013.6611045

117. Shin H, Choi B, Kim D, Cho J (2014) Robust sleep quality quantification method for a personal handheld device. Telemed. e-Health. https://doi.org/10.1089/tmj.2013.0216

118. Szczepański A, Saeed K (2014) A mobile device system for early warning of ECG anomalies. Sensors (Switzerland). https://doi.org/10.3390/s140611031

119. Sun B, Wang Y, Banda J (2014) Gait characteristic analysis and identification based on the iPhone's accelerometer and gyrometer. Sensors (Switzerland). https://doi.org/10.3390/s140917037

120. Villarejo MV, García JM, Zapirain BG, Zorrilla AM (2014) Technological solution for determining gait parametersusing pressure sensors: A case study of multiple sclerosis patients. In: Bio-Medical Materials and Engineering. https://doi.org/10.3233/BME-141177 
121. Seeger C, Van Laerhoven K, Buchmann A (2015) My health assistant: An event-driven middleware for multiple medical applications on a smartphone-mediated body sensor network. IEEE J Biomed Heal Informatics. https://doi.org/10.1109/JBHI.2014.2326604

122. Tartz R, Vartak A, King J, Fowles D (2015) Effects of grip force on skin conductance measured from a handheld device. Psychophysiology. https://doi.org/10.1111/psyp.12237

123. Kwon S, Kim J, Kang S, Lee Y, Baek H, Park K (2014) CardioGuard: A brassiere-based reliable ECG monitoring sensor system for supporting daily smartphone healthcare applications. Telemed. e-Health. https://doi.org/10.1089/tmj.2014.0008

124. Alshurafa N, Eastwood JA, Pourhomayoun M, Liu JJ, Sarrafzadeh M (2014) Remote health monitoring: Predicting outcome success based on contextual features for cardiovascular disease. In: 2014 36th Annual International Conference of the IEEE Engineering in Medicine and Biology Society, EMBC 2014. https://doi.org/10.1109/EMBC.2014.6943953

125. Kwon S, Kang S, Lee Y, Yoo C, Park K (2014) Unobtrusive monitoring of ECG-derived features during daily smartphone use. In: 2014 36th Annual International Conference of the IEEE Engineering in Medicine and Biology Society, EMBC 2014. https://doi.org/10.1109/EMBC.2014.6944738

126. Capela NA, Lemaire ED, Baddour N (2015) Feature selection for wearable smartphone-based human activity recognition with able bodied, elderly, and stroke patients. PLoS One. https://doi.org/10.1371/ journal.pone.0124414

127. Miao F, He Y, Liu J, Li Y, Ayoola I (2015) Identifying typical physical activity on smartphone with varying positions and orientations. Biomed Eng Online 14:32. https://doi.org/10.1186/s12938-0150026-4

128. Kim A, Kim J, Rietdyk S, Ziaie B (2015) A wearable smartphone-enabled camera-based system for gait assessment. Gait Posture. https://doi.org/10.1016/j.gaitpost.2015.05.001

129. Ghose S, Mitra J, Karunanithi M, Dowling J (2015) Human activity recognition from smart-phone sensor data using a multi-class ensemble learning in home monitoring. In: Studies in health technology and informatics. https://doi.org/10.3233/978-1-61499-558-6-62

130. Kay MS, Iaione F (2015) Viability of a bioelectrical signal acquisition system energized by cellphone with NFC. In: Studies in Health Technology and Informatics. https://oi.org/10.3233/978-1-61499-564$7-900$

131. Kostikis N, Hristu-Varsakelis D, Arnaoutoglou M, Kotsavasiloglou C (2015) A smartphone-based tool for assessing parkinsonian hand tremor. IEEE J Biomed Heal Informatics. https://doi.org/10.1109/JBHI. 2015.2471093

132. Otoom M, Alshraideh H, Almasaeid HM, López-De-Ipiña D, Bravo J (2015) Real-time statistical modeling of blood sugar. J Med Syst. https://doi.org/10.1007/s10916-015-0301-8

133. Ku HH (2015) Design of a Golf Swing Injury Detection and Evaluation open service platform with Ontology-oriented clustering case-based reasoning mechanism. In: Technology and Health Care 24: S261-S270. https://doi.org/10.3233/THC-151083

134. Park HS, Cho H, Kim HS (2016) Development of a multi-agent M-health application based on various protocols for chronic disease self-management. J Med Syst. https://doi.org/10.1007/s10916-015-0401-5

135. Brugués A et al (2016) Processing diabetes mellitus composite events in MAGPIE. J. Med. Syst. https:// doi.org/10.1007/s10916-015-0377-1

136. Orr K et al (2015) Validity of smartphone pedometer applications Public Health. BMC Res Notes. https://doi.org/10.1186/s13104-015-1705-8

137. Serhani MA, El Menshawy M, Benharref A (2016) SME2EM: Smart mobile end-to-end monitoring architecture for life-long diseases. Comput Biol Med. https://doi.org/10.1016/j.compbiomed.2015.11. 009

138. Gu F, Kealy A, Khoshelham K, Shang J (2015) User-independent motion state recognition using smartphone sensors," Sensors (Switzerland). https://doi.org/10.3390/s151229821

139. Lemaire ED, Tundo MD, Baddour N (2015) Evaluation of a smartphone-based human activity recognition system in a daily living environment. J Vis Exp. https://doi.org/10.3791/53004

140. De Cillisy F, De Simioy F, Guidoy F, Incalzi RA, Setolay R (2015) Fall-detection solution for mobile platforms using accelerometer and gyroscope data. In: Proceedings of the Annual International Conference of the IEEE Engineering in Medicine and Biology Society, EMBS. https://oi.org/10. 1109/EMBC.2015.7319203

141. Tange Y, Takeno S, Hori J (2015) Development of the obstacle detection system combining orientation sensor of smartphone and distance sensor. In: Proceedings of the Annual International Conference of the IEEE Engineering in Medicine and Biology Society, EMBS. https://doi.org/10.1109/EMBC.2015. 7319929 
142. Estrada L, Torres A, Sarlabous L, Jan R (2015) Respiratory signal derived from the smartphone built-in accelerometer during a Respiratory Load Protocol. In: Proceedings of the Annual International Conference of the IEEE Engineering in Medicine and Biology Society, EMBS. https://doi.org/10. 1109/EMBC.2015.7319947

143. Duregger K, Hayn D, Morak J, Ladenstein R, Schreier G (2015) An mHealth system for toxicity monitoring of paediatric oncological patients using Near Field Communication technology. In Proceedings of the Annual International Conference of the IEEE Engineering in Medicine and Biology Society, EMBS. https://doi.org/10.1109/EMBC.2015.7319966

144. Hernandez J, McDuff DJ, Picard RW (2015) Biophone: Physiology monitoring from peripheral smartphone motions. In: Proceedings of the Annual International Conference of the IEEE Engineering in Medicine and Biology Society, EMBS. https://doi.org/10.1109/EMBC.2015.7320048

145. Garde A, Dehkordi P, Wensley D, Ansermino JM, Dumont GA (2015) Pulse oximetry recorded from the Phone Oximeter for detection of obstructive sleep apnea events with and without oxygen desaturation in children. In: Proceedings of the Annual International Conference of the IEEE Engineering in Medicine and Biology Society, EMBS. https://doi.org/10.1109/EMBC.2015.7320174

146. Capela NA, Lemaire ED, Baddour N, Rudolf M, Goljar N, Burger H (2016) Evaluation of a smartphone human activity recognition application with able-bodied and stroke participants. J Neuroeng Rehabil. https://doi.org/10.1186/s12984-016-0114-0

147. Nam Y, Kong Y, Reyes B, Reljin N, Chon KH (2016) Monitoring of heart and breathing rates using dual cameras on a smartphone. PLoS One. https://doi.org/10.1371/journal.pone.0151013

148. Zhang Y, Liu H, Su X, Jiang P, Wei D (2015) Remote mobile health monitoring system based on smart phone and browser/server structure. J Healthc Eng. https://doi.org/10.1260/2040-2295.6.4.717

149. Cheatham SW, Kolber MJ, Ernst MP (2015) Concurrent validity of resting pulse-rate measurements: A comparison of 2 smartphone applications, the polar $\mathrm{H} 7$ belt monitor, and a pulse oximeter with bluetooth. J Sport Rehabil. https://doi.org/10.1123/jsr.2013-0145

150. Schmidt PE et al (2015) Impact of introducing an electronic physiological surveillance system on hospital mortality. BMJ Qual Saf. https://doi.org/10.1136/bmjqs-2014-003073

151. Arsand E, Muzny M, Bradway M, Muzik J, Hartvigsen G (2015) Performance of the first combined smartwatch and smartphone diabetes diary application study. J Diabetes Sci Technol. https://doi.org/10. $1177 / 1932296814567708$

152. Haberman ZC et al (2015) Wireless smartphone ECG enables large-scale screening in diverse populations. J Cardiovasc Electrophysiol. https://doi.org/10.1111/jce.12634

153. Peritz DC, Howard A, Ciocca M, Chung EH (2015) Smartphone ECG AIDS real time diagnosis of palpitations in the competitive college athlete. J Electrocardiol. https://doi.org/10.1016/j.jelectrocard. 2015.07.010

154. McManus DD et al (2016) PULSE-SMART: Pulse-based arrhythmia discrimination using a novel smartphone application. J Cardiovasc Electrophysiol. https://doi.org/10.1111/jce.12842

155. Guidi A et al (2015) Smartphone application for the analysis of prosodic features in running speech with a focus on bipolar disorders: System performance evaluation and case study. Sensors (Switzerland). https://doi.org/10.3390/s151128070

156. Flatt AA, Esco MR (2015) Smartphone-derived heart-rate variability and training load in a women's soccer team. Int J Sports Physiol Perform. https://doi.org/10.1123/ijspp.2014-0556

157. Romyn G, Robey E, Dimmock JA, Halson SL, Peeling P (2016) Sleep, anxiety and electronic device use by athletes in the training and competition environments. Eur J Sport Sci. https://doi.org/10.1080/ 17461391.2015.1023221

158. Kalantarian H, Sarrafzadeh M (2015) Audio-based detection and evaluation of eating behavior using the smartwatch platform. Comput Biol Med. https://doi.org/10.1016/j.compbiomed.2015.07.013

159. Choo KY, Ling HC, Lo YC, Yap ZH, Pua JS, Phan RCW, Goh VT (2015) Android based selfdiagnostic electrocardiogram system for mobile healthcare. In: Technology and health care, vol 23, pp S435-S442. https://doi.org/10.3233/THC-150980

160. Mohino-Herranz I, Gil-Pita R, Ferreira J, Rosa-Zurera M, Seoane F (2015) Assessment of mental, emotional and physical stress through analysis of physiological signals using smartphones. Sensors (Switzerland). https://doi.org/10.3390/s151025607

161. Trindade IG, Martins F, Dias R, Oliveira C, Machado Da Silva J (2015) Novel textile systems for the continuous monitoring of vital signals: Design and characterization. In: Proceedings of the Annual International Conference of the IEEE Engineering in Medicine and Biology Society, EMBS. https:/doi. org/10.1109/EMBC.2015.7319207 
162. Artetxe A, Beristain A, Kabongo L (2014) Activity classification using mobile phone based motion sensing and distributed computing. In: Studies in Health Technology and Informatics. https://oi.org/10. 3233/978-1-61499-474-9-1

163. Cheffena M (2016) Fall Detection Using Smartphone Audio Features. IEEE J Biomed Heal Informatics. https://doi.org/10.1109/JBHI.2015.2425932

164. Barreira TV, Hamilton MT, Craft LL, Gapstur SM, Siddique J, Zderic TW (2016) Intra-individual and inter-individual variability in daily sitting time and MVPA. J Sci Med Sport 19:476-481. https://doi.org/ 10.1016/j.jsams.2015.05.004

165. Garcia-Ceja E, Osmani V, Mayora O (2016) Automatic stress detection in working environments from smartphones' accelerometer data: A first step. IEEE J Biomed Heal Informatics. https:/doi.org/10.1109/ JBHI.2015.2446195

166. Raknim P, Lan K (2016) Gait monitoring for early neurological disorder detection using sensors in a smartphone: Validation and a case study of parkinsonism. Telemed e-Health. https://oi.org/10.1089/ tmj.2015.0005

167. Rosenberger ME, Buman MP, Haskell WL, McConnell MV, Carstensen LL (2016) Twenty-four hours of sleep, sedentary behavior, and physical activity with nine wearable devices. Med Sci Sports Exerc. https://doi.org/10.1249/MSS.0000000000000778

168. Gordon BA, Bruce L, Benson AC (2016) Physical activity intensity can be accurately monitored by smartphone global positioning system 'app'. Eur J Sport Sci. https://doi.org/10.1080/17461391.2015. 1105299

169. Major MJ, Alford M (2016) Validity of the iPhone M7 motion co-processor as a pedometer for ablebodied ambulation. J Sports Sci. https://doi.org/10.1080/02640414.2016.1189086

170. Wang Y, Doleschel S, Wunderlich R, Heinen S (2016) Evaluation of digital compressed sensing for real-time wireless ECG system with bluetooth low energy. J Med Syst 40(7):170. https://doi.org/10. 1007/s10916-016-0526-1

171. Li P, Wang Y, Tian Y, Zhou TS, Li JS (2017) An automatic user-adapted physical activity classification method using smartphones. IEEE Trans Biomed Eng. https://doi.org/10.1109/TBME.2016.2573045

172. Sareen S, Sood SK, Gupta SK (2016) An automatic prediction of epileptic seizures using cloud computing and wireless sensor networks. J Med Syst. https://doi.org/10.1007/s10916-016-0579-1

173. Koo SK, Kwon SB, Kim YJ, Moon JS, Kim YJ, Jung SH (2017) Acoustic analysis of snoring sounds recorded with a smartphone according to obstruction site in OSAS patients. Eur Arch Oto-RhinoLaryngology. https://doi.org/10.1007/s00405-016-4335-4

174. Cvetković B, Janko V, Romero AE, Kafalı Ö, Stathis K, Luštrek M (2016) Activity recognition for diabetic patients using a smartphone. J Med Syst. https://doi.org/10.1007/s10916-016-0598-y

175. Sun A, Venkatesh AG, Hall DA (2016) A multi-technique reconfigurable electrochemical biosensor: enabling personal health monitoring in mobile devices. IEEE Trans Biomed Circuits Syst. https:/doi. org/10.1109/TBCAS.2016.2586504

176. Lemoyne R, Mastroianni T (2016) Implementation of a smartphone as a wireless gyroscope platform for quantifying reduced arm swing in hemiplegie gait with machine learning classification by multilayer perceptron neural network. Proceedings of the Annual International Conference of the IEEE Engineering in Medicine and Biology Society, EMBS. https://doi.org/10.1109/EMBC.2016.7591269

177. Garde A, Dekhordi P, Ansermino JM, Dumont GA (2016) Identifying individual sleep apnea/ hypoapnea epochs using smartphone-based pulse oximetry. In Proceedings of the Annual International Conference of the IEEE Engineering in Medicine and Biology Society, EMBS. https:// doi.org/10.1109/EMBC.2016.7591408

178. Nemati E, Sideris K, Kalantarian H, Sarrafzadeh M (2016) A dynamic data source selection system for smartwatch platform. In Proceedings of the Annual International Conference of the IEEE Engineering in Medicine and Biology Society, EMBS. https://doi.org/10.1109/EMBC.2016.7592094

179. Cheng Q et al (2016) Classification models for pulmonary function using motion analysis from phone sensors. AMIA Annu Symp Proc

180. Kayyali R et al (2016) Qualitative investigation into a wearable system for chronic obstructive pulmonary disease: The stakeholders' perspective. BMJ Open. https://doi.org/10.1136/bmjopen-2016011657

181. Liang PC, Krause P (2016) Smartphone-Based real-time indoor location tracking with 1-m precision. IEEE J Biomed Heal Informatics. https://doi.org/10.1109/JBHI.2015.2500439

182. Harrison B et al (2016) MyPectus: First-in-human pilot study of remote compliance monitoring of teens using dynamic compression bracing to correct pectus carinatum. J Pediatr Surg. https://doi.org/10.1016/ j.jpedsurg.2015.11.007 
183. Alshurafa N, Sideris C, Pourhomayoun M, Kalantarian H, Sarrafzadeh M, Eastwood JA (2017) Remote health monitoring outcome success prediction using baseline and first month intervention data. IEEE J Biomed Heal, Informatics. https://doi.org/10.1109/JBHI.2016.2518673

184. Leong JY, Wong JE (2017) Accuracy of three Android-based pedometer applications in laboratory and free-living settings. J Sports Sci. https://doi.org/10.1080/02640414.2016.1154592

185. Abdullah S, Matthews M, Frank E, Doherty G, Gay G, Choudhury T (2016) Automatic detection of social rhythms in bipolar disorder. J Am Med Informatics Assoc. https://doi.org/10.1093/jamia/ocv200

186. Taylor D et al (2016) Quantified-self for obesity: Physical activity behaviour sensing to improve health outcomes. In: Studies in Health Technology and Informatics. https://doi.org/10.3233/978-1-61499-625$5-414$

187. Cochrane SK et al (2017) Association of accelerometry-measured physical activity and cardiovascular events in mobility-limited older adults: The LIFE (Lifestyle Interventions and Independence for Elders) study. J. Am. Heart Assoc. https://doi.org/10.1161/JAHA.117.007215

188. Choi J, Choi C, Ko H, Kim P (2016) Intelligent healthcare service using health lifelog analysis. J Med Syst. https://doi.org/10.1007/s10916-016-0534-1

189. Brucal SGE, Clamor GKD, Pasiliao LAO, Soriano JPF, Varilla LPM (2016) Portable electrocardiogram device using Android smartphone. In: Proceedings of the Annual International Conference of the IEEE Engineering in Medicine and Biology Society, EMBS. https://doi.org/10.1109/EMBC.2016.7590751

190. Cancela J, et al (2016) Monitoring of motor and non-motor symptoms of Parkinson's disease through a mHealth platform. In: Proceedings of the Annual International Conference of the IEEE Engineering in Medicine and Biology Society, EMBS. https://oi.org/10.1109/EMBC.2016.7590789

191. Altini M, Amft O (2016) HRV4Training: Large-scale longitudinal training load analysis in unconstrained free-living settings using a smartphone application. In: Proceedings of the Annual International Conference of the IEEE Engineering in Medicine and Biology Society, EMBS. https://oi.org/10.1109/ EMBC. 2016.7591265

192. Pendergast FJ, Ridgers ND, Worsley A, McNaughton SA (2017) Evaluation of a smartphone food diary application using objectively measured energy expenditure. Int J Behav Nutr Phys Act. https://doi.org/ 10.1186/s12966-017-0488-9

193. Lowres $\mathrm{N}$ et al (2016) Self-monitoring for atrial fibrillation recurrence in the discharge period postcardiac surgery using an iPhone electrocardiogram. Eur J Cardio-thoracic Surg. https://doi.org/10.1093/ ejcts/ezv486

194. Murnane EL et al (2016) Self-monitoring practices, attitudes, and needs of individuals with bipolar disorder: Implications for the design of technologies to manage mental health. J Am Med Informatics Assoc. https://doi.org/10.1093/jamia/ocv165

195. Reyes BA, Reljin N, Kong Y, Nam Y, Chon KH (2017) Tidal volume and instantaneous respiration rate estimation using a volumetric surrogate signal acquired via a smartphone camera. IEEE J Biomed Heal Informatics. https://doi.org/10.1109/JBHI.2016.2532876

196. Reyes BA, Reljin N, Kong Y, Nam Y, Ha S, Chon KH (2016) Employing an incentive spirometer to calibrate tidal volumes estimated from a smartphone camera. Sensors (Switzerland). https://doi.org/10. 3390/s16030397

197. Lee JS, Lin KW, Syue JL (2016) Smartphone-based heart-rate measurement using facial images and a spatiotemporal alpha-trimmed mean filter. In: Technology and Health Care vol 24, pp S777-S783. https://doi.org/10.3233/THC-161207

198. Zheng J, Ha C, Zhang Z (2017) Design and evaluation of a ubiquitous chest-worn cardiopulmonary monitoring system for healthcare application: A pilot study. Med Biol Eng Comput. https://doi.org/10. 1007/s11517-016-1518-5

199. Carreiro S, Wittbold K, Indic P, Fang H, Zhang J, Boyer EW (2016) Wearable biosensors to detect physiologic change during opioid use. J Med Toxicol. https://doi.org/10.1007/s13181-016-0557-5

200. Lipert A, Jegier A (2017) Comparison of different physical activity measurement methods in adults aged 45 to 64 years under free-living conditions. Clin J Sport Med. https://doi.org/10.1097/JSM. 0000000000000362

201. Smieszek T, Castell S, Barrat A, Cattuto C, White PJ, Krause G (2016) Contact diaries versus wearable proximity sensors in measuring contact patterns at a conference: Method comparison and participants' attitudes. BMC Infect Dis. https://doi.org/10.1186/s12879-016-1676-y

202. Hickey A et al (2016) Validity of a wearable accelerometer to quantify gait in spinocerebellar ataxia type 6. Physiol. Meas. https://doi.org/10.1088/0967-3334/37/11/N105

203. Yang Z, Zhou Q, Lei L, Zheng K, Xiang W (2016) An IoT-cloud based wearable ECG monitoring system for smart healthcare. J Med Syst. https:/doi.org/10.1007/s10916-016-0644-9 
204. Jantunen $\mathrm{H}$ et al (2017) Objectively measured physical activity and physical performance in old age. Age Ageing. https://doi.org/10.1093/ageing/afw194

205. Iqbal $\mathrm{MH}$ et al (2016) The effectiveness of Google GLASS as a vital signs monitor in surgery: A simulation study. Int J Surg. https://doi.org/10.1016/j.ijsu.2016.11.013

206. Santoyo-Ramón JA, Casilari E, Cano-García JM (2018) Analysis of a smartphone-based architecture with multiple mobility sensors for fall detection with supervised learning. Sensors (Switzerland). https:// doi.org/10.3390/s18041155

207. Brodie MA, Okubo Y, Annegarn J, Wieching R, Lord SR, Delbaere K (2017) Disentangling the health benefits of walking from increased exposure to falls in older people using remote gait monitoring and multi-dimensional analysis. Physiol Meas. https://doi.org/10.1088/1361-6579/38/1/45

208. Hickey A, Del Din S, Rochester L, Godfrey A (2017) Detecting free-living steps and walking bouts: Validating an algorithm for macro gait analysis. Physiol Meas. https://doi.org/10.1088/1361-6579/38/1/ N1

209. Hegde N, Melanson E, Sazonov E (2016) Development of a real time activity monitoring Android application utilizing SmartStep. In: Proceedings of the Annual International Conference of the IEEE Engineering in Medicine and Biology Society, EMBS. https://doi.org/10.1109/EMBC.2016.7591089

210. Alqudah $\mathrm{H}$ et al (2016) Cardiovascular fitness strengthening using portable device. In: Proceedings of the Annual International Conference of the IEEE Engineering in Medicine and Biology Society, EMBS. https://doi.org/10.1109/EMBC.2016.7591285

211. Voss C, Gardner RF, Dean PH, Harris KC (2017) Validity of commercial activity trackers in children with congenital heart disease. Can J Cardiol. https://doi.org/10.1016/j.cjca.2016.11.024

212. Middelweerd A, Van Der Ploeg HP, Van Halteren A, Twisk JWR, Brug J, Te Velde SJ (2017) A validation study of the fitbit one in daily life using different time intervals. Med Sci Sports Exerc. https:// doi.org/10.1249/MSS.0000000000001225

213. Lin X, Seet BC (2017) Battery-free smart sock for abnormal relative plantar pressure monitoring. IEEE Trans Biomed Circuits Syst. https://doi.org/10.1109/TBCAS.2016.2615603

214. Al-Kurwi ASA, Bos A, Kuitert RB (2017) Overjet reduction in relation to wear time with the van Beek activator combined with a microsensor. Am J Orthod Dentofac Orthop. https://doi.org/10.1016/j.ajodo. 2016.06 .046

215. Townhill $\mathrm{J}$ et al (2016) Using Actiwatch to monitor circadian rhythm disturbance in Huntington' disease: A cautionary note. J Neurosci Methods 265:13-18. https://doi.org/10.1016/j.jneumeth.2016. 01.009

216. Nelson MB, Kaminsky LA, Dickin DC, Montoye AHK (2016) Validity of consumer-based physical activity monitors for specific activity types. Med Sci Sports Exerc. https://doi.org/10.1249/MSS. 0000000000000933

217. Chan NY, Choy CC (2017) Screening for atrial fibrillation in 13122 Hong Kong citizens with smartphone electrocardiogram. Heart. https://doi.org/10.1136/heartjnl-2016-309993

218. Lee H et al (2017) Dedicated cardiac rehabilitation wearable sensor and its clinical potential. PLoS One. https://doi.org/10.1371/journal.pone.0187108

219. Kim EK et al (2019) The effect of a smartphone-based, patient-centered diabetes care system in patients with type 2 diabetes: A randomized, controlled trial for 24 weeks. Diabetes Care. https://doi.org/10. 2337/dc17-2197

220. Baskaran V, Prescod F, Dong L (2015) A smartphone-based cloud computing tool for managing type 1 diabetes in ontarians. Can J Diabetes 9:200-203. https://doi.org/10.1016/j.jcjd.2015.04.002

221. Jarad NA, Sund ZM (2011) Telemonitoring in chronic obstructive airway disease and adult patients with cystic fibrosis. J Telemed Telecare 17:127-132. https://doi.org/10.1258/jtt.2010.100309

222. Burke LE et al (2009) SMART trial: A randomized clinical trial of self-monitoring in behavioral weight management-design and baseline findings. Contemp Clin Trials 30:540-551. https://doi.org/10.1016/j. cct.2009.07.003

223. Timmis A et al (2018) European society of cardiology: Cardiovascular disease statistics 2017. Eur Heart J. https://doi.org/10.1093/eurheartj/ehx628.

224. Vuorela T, Seppä VP, Vanhala J, Hyttinen J (2010) Design and implementation of a portable long-term physiological signal recorder. IEEE Trans Inf Technol Biomed. https://doi.org/10.1109/TITB.2010. 2042606

225. Hernández N, Favela J (2015) Estimating the perception of physical fatigue among older adults using mobile phones. In: Lecture notes in computer science (including subseries lecture notes in artificial intelligence and lecture notes in bioinformatics). https://doi.org/10.1007/978-3-319-24195-17 
226. Atallah L, Lo B, King R, Yang GZ (2010) Sensor placement for activity detection using wearable accelerometers. In: 2010 International Conference on Body Sensor Networks, BSN 2010. https://doi. org/10.1109/BSN.2010.23

227. Edy Susanto M (2019) Improving the evidence for mobile health. J Chem Inf Model 53(9):1689-1699. https://doi.org/10.1017/CBO9781107415324.004

228. Akobeng AK (2005) Understanding randomised controlled trials. Arch Dis Child. https://doi.org/10. 1136/adc.2004.058222

229. Shuren J, Patel B, Gottlieb S (2018) FDA regulation of mobile medical apps. JAMA - Journal of the American Medical Association. https://doi.org/10.1001/jama.2018.8832

230. Kjeldskov J, Graham C (2003) A review of mobile HCI research methods. Lecture Notes in Computer Science (including subseries Lecture Notes in Artificial Intelligence and Lecture Notes in Bioinformatics).

Publisher's Note Springer Nature remains neutral with regard to jurisdictional claims in published maps and institutional affiliations.

\section{Affiliations}

\section{N. Hernandez ${ }^{1}$ - L. Castro ${ }^{2} \cdot$ J. Medina-Quero ${ }^{3} \cdot$ J. Favela $^{4} \cdot$ L. Michan ${ }^{5} \cdot$ W. Ben. Mortenson $^{6}$}

L. Castro

luis.castro@acm.org

J. Medina-Quero

jmquero@ujaen.es

J. Favela

favela@cicese.mx

L. Michan

laylamichan@ciencias.unam.mx

W. Ben. Mortenson

ben.mortenson@ubc.ca

School of Computing, Campus Jordanstown, Ulster University, Newtownabbey BT37-0QB, UK

2 Department of Computing and Design, Sonora Institute of Technology (ITSON), Ciudad Obregón 85000, Mexico

3 Department of Computer Science, Campus Las Lagunillas, University of Jaen, Jaén 23071, Spain

4 Department of Computer Science, Ensenada Centre for Scientific Research and Higher Education, Ensenada 22860, Mexico

5 Department of Comparative Biology, National Autonomous University of Mexico, Mexico City 04510 , Mexico

6 International Collaboration on Repair Discoveries and GF Strong Rehabilitation Research Program, University of British Columbia, Vancouver V6T-1Z4, Canada 